\title{
NEOLÍTICO Y CALCOLÍTICO EN HUECAS (TOLEDO). EL TÚMULO DE CASTILLEJO. CAMPAÑA DE 1998
}

\author{
NEOLITHIC AND CHALCOLITHIC \\ IN HUECAS (TOLEDO). THE TOMB \\ OF EL CASTILLEJO. THE 1998 CAMPAIGN
}

PRIMITIVA BUENO RAMÍREZ $(*)$

RODRIGO DE BALBÍN BEHRMANN (*)

ROSA BARROSO BERMEJO (*)

JUAN MANUEL ROJAS RODRÍGUEZ-MALO $(* *)$

RAMÓN VILLA GONZÁLEZ (**)

RODOLFO FÉLIX LÓPEZ (***)

SALVADOR ROVIRA LLORENS $(* * * *)$

\section{RESUMEN}

La excavación del túmulo del Castillejo, en Huecas, ha proporcionado restos óseos de al menos nueve individuos. La disposición de los cadáveres, la visibilidad del túmulo y su proximidad a un poblado importante y a otros enterramientos en cueva artificial, plantea numerosas cuestiones acerca de la interpretación tradicional del mundo funerario neolítico y calcolítico meseteño. Su claro colectivismo y la envergadura del túmulo relacionan este enterramiento con el megalitismo, pese a carecer de estructuras de esa índole. La posible conexión simbólica entre los enterrados y una subestructura habitacional, añade interés a los resultados de una investigación que esperamos poder continuar.

\footnotetext{
ABSTRACT

The excavation of the tomb of El Castillejo, at Huecas, has provided bone remains of at least nine individuals. The arrangement of the corpses, the visibility of the tomb and

(*) Área de Prehistoria.Universidad de Alcalá de Henares. Colegios, 2. 28801 Alcalá de Henares Toledo.

(*) Arqueología y Patrimonio. Nuncio Viejo, 7. 45002

(***) Ayuntamiento de Huecas. 45511 Huecas. Toledo.

$(* * * *)$ Jefe del Departamento de Conservación del Museo Arqueológico Nacional. Serrano,13. 28001 Madrid.

El artículo fue remitido en su versión final el 25-X-99.
}

its proximity to an important village and to artificial caves, raises numerous problems about the traditional interpretation of the Neolithic funerary world and the Chalcolithic in the Meseta. Its clear collectivism and the importance of the tomb relates this burial to the Megalithic culture, in spite of lacking large stone structures. The possible symbolic connection among the buried and an early dwelling structure, adds interest to the results of an investigation that we hope to continue.

Palabras clave: Enterramientos colectivos. Megalitismo. Habitat. Campaniforme. Metal.

Key words: Collective burials. Megalithic culture. Habitat. Bell Beaker. Metal.

\section{ANTECEDENTES DE NUESTRO TRABAJO}

La excavación en el túmulo del Castillejo de Huecas se deriva de una serie de acciones arqueológicas previas emprendidas por la Diputación de Toledo y por la Junta de Castilla-La Mancha.

La Diputación financió en su día el estudio sobre el origen e historia del pueblo de Huecas (Esteban et alii, 1998). En un primer capítulo del mismo dedicado a la Prehistoria del lugar, Carrobles (Esteban et alii, 1998: 25) menciona la existencia del 
túmulo del Castillejo de Huecas, interpretándolo como un posible dolmen. Señala el mismo autor, abundantes materiales líticos y cerámicos en una tierra próxima, El Fontarrón (Esteban et alii, 1998: 26), zona que nosotros interpretamos como un poblado conectado con las ocupaciones funerarias que vamos a describir.

Por otro lado, la Junta de Castilla-La Mancha había enviado a los arqueólogos J.M. Rojas y R. Villa a realizar un informe sobre la apertura de un camino al sur del pueblo que afectaba a una serie de tumbas de la Era. Su estancia en Huecas los puso en contacto con R. Félix, gran conocedor del terreno y apasionado defensor de la riqueza arqueológica de su pueblo, el cual les informó de la presencia, interés y peligro del túmulo del Castillejo.

Efectivamente, el túmulo se encuentra en una zona que quedará afectada por los inminentes planes de regadío por lo que la información arqueológica era de todo punto necesaria y urgente. J.M. Rojas y R. Villa realizaron un corte en el mismo localizando restos humanos acompañados de elementos líticos y cerámicos.

De este modo comenzaron los trámites con la Junta de Castilla-La Mancha interesada por cumplir con el preceptivo informe arqueológico, teniendo lugar la primera campaña en el mes de Septiembre de 1998.

\section{UBICACIÓN DE LOS YACIMIENTOS NEOLÍTICOS Y CALCOLÍTICOS DE HUECAS. POTENCIALIDADES DEL TERRITORIO}

Una de las primeras características del Castillejo es su posición en el paisaje. Destaca en el valle que se forma entre los arroyos de Barcience y Rielves. Su visión desde el poblado, con la laguna delante, nos remite a un "escenario" (Criado y Villoch, 1998) de gran fuerza visual, evidentemente buscado por los realizadores del túmulo.

El túmulo del Castillejo no es el único yacimiento detectado en término de Huecas (Fig. 1). Junto a él, se localiza el gran poblado del Fontarrón que se extiende por una superficie de más de $1 \mathrm{~km}$, aunque no podremos precisar más hasta conocer realmente su perímetro. En superficie aparece gran cantidad de material: hachas pulimentadas, cerámicas lisas, pintadas e incisas campaniformes, molinos, molederas y puntas de flecha. Carrobles (1998: 43) muestra algunas piezas, a las que habría que añadir las localizadas por R. Félix. De las prospecciones realizadas por J.M. Rojas y R. Villa procede un fragmento de borde de plato engrosado con restos de cobre y de fuerte calentamiento que ha sido analizado por Salvador Rovira, interpretándolo como un fragmento de vasija horno. Este dato permite integrar el poblado del Fontarrón entre los poblados campaniformes del Tajo interior con metalurgia, aunque creemos más que factible que posea un nivel de habitación anterior, por lo que podemos deducir de otros materiales.

Si nos atenemos a los presupuestos tipológicos que han planteado otros autores para el poblamiento del sector (Alvaro et alii, 1987; Carrobles, 1990; Carrobles y Mendez, 1991; Carrobleset alii, 1994; Muñoz, 1993;Muñoz et alii, 1995), tendríamos que hablar de una etapa precampaniforme y otra campaniforme.

En una altura mayor y al Este del túmulo, en el valle de las Higueras, se localizan unas estructuras que interpretamos como cuevas artificiales, de las que proceden dos puñalitos de cobre, uno de ellos con espigo (Lám. IA), una punta Palmela (Lám. IB), cuencos campaniformes incisos, mucha cerámica lisa, cuentas de piedra verde (Lám. IC) y restos humanos. A la espera del resultado de nuestras excavaciones de la campaña de 1999, las cuevas artificiales de Huecas se muestran como un argumento de enorme interés para revalorizar la vía del Tajo respecto a la interpretación del Calcolítico meseteño. La riqueza de los ajuares presenta una faceta social hasta ahora inédita en los conjuntos interiores, pues la capacidad de apropiación de excedentes que podemos deducir de la presencia de materiales de prestigio es muy notoria.

Las cuevas artificiales del Valle de las Higueras suponen además una ratificación de nuestra interpretación (Bueno Ramírez et alii, 1999: 103) de Yuncos (Ruiz Fernández, 1975), como cueva artificial con piezas que contribuyen a afianzar la conexión cultural entre los grupos de la zona de Lisboa y los del interior de la Península Ibérica.

El conjunto de los materiales metálicos descritos más el punzón de cobre que procede de la excavación del túmulo, constituye una evidencia muy sólida acerca de la importancia de la metalurgia en la zona, dando nuevo valor a los datos más o menos dispersos de que disponíamos hasta la actualidad en la provincia de Toledo (Alvaro, 1987: 29; Harrison, 1974; Rovira et alii, 1997).

La tabla 1 expresa los resultados del análisis llevado a cabo por S. Rovira en el Laboratorio del

T. P., 56, n. ${ }^{\circ}$ 2, 1999 

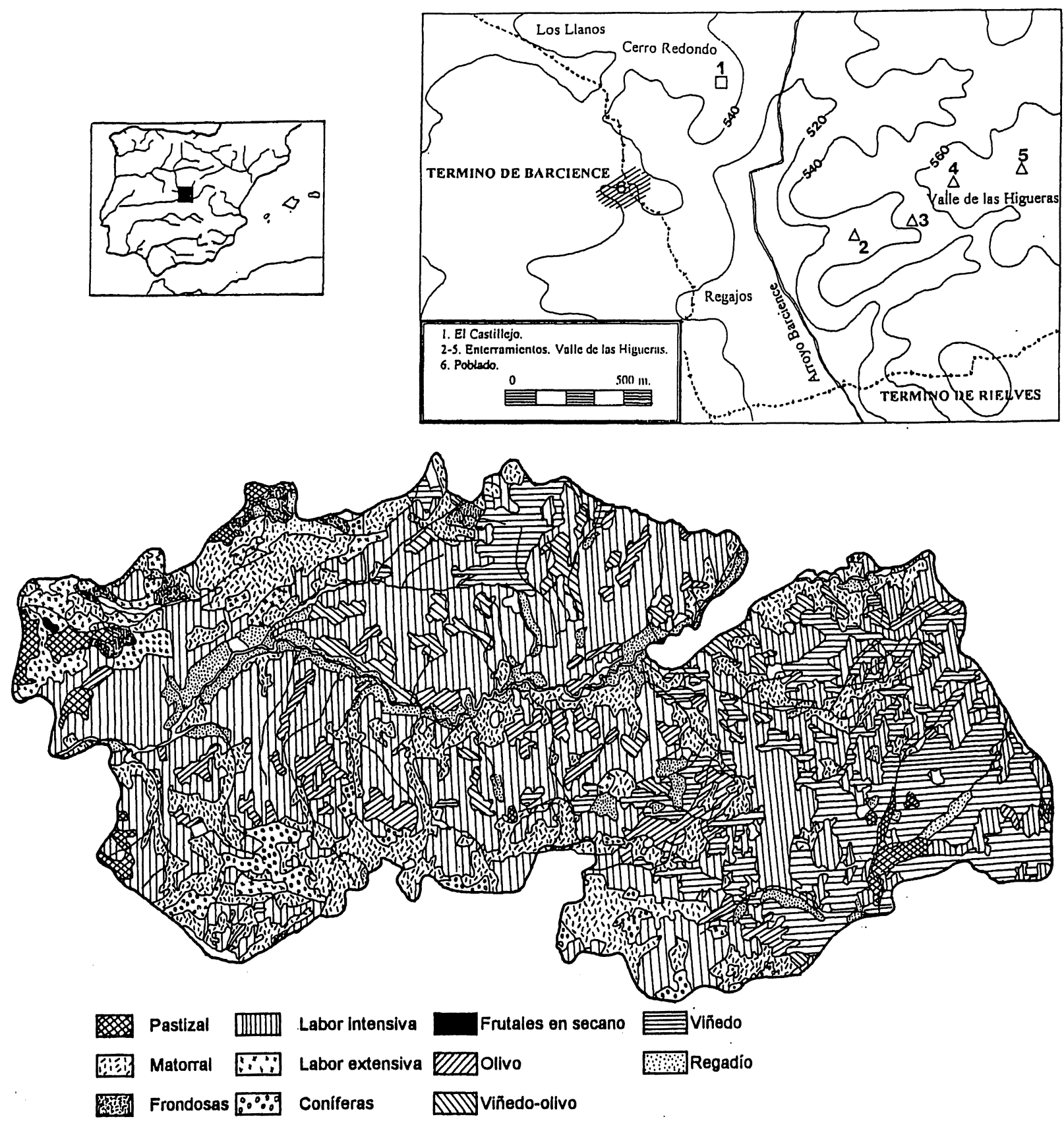

Fig. 1. Situación de los yacimientos neolíticos y calcolíticos en el término de Huecas (Toledo) y mapa de dedicación actual de suelos.

\begin{tabular}{|l|l|c|c|c|c|c|c|c|c|c|c|}
\hline Análisis & \multicolumn{1}{|c|}{ Objeto } & Fe & Ni & $\mathbf{C u}$ & $\mathbf{Z n}$ & $\mathbf{A s}$ & $\mathbf{A g}$ & $\mathbf{S n}$ & $\mathbf{S b}$ & $\mathbf{P b}$ & $\mathbf{B i}$ \\
\hline CH1 & Punzón & 0,1 & 0,1 & 99,5 & nd & 0,2 & nd & nd & 0,1 & nd & nd \\
\hline VH-1 & Punta Palmela & 0,1 & nd & 98,9 & nd & 0,8 & 0,005 & nd & 0,15 & nd & nd \\
\hline VH-3 & Puñal lengüeta (pequeño) & 0,05 & nd & 98,6 & nd & 1,2 & nd & nd & 0,12 & nd & nd \\
\hline VH-2 & Puñal lengüeta (grande) & 0,1 & 0,05 & 98,3 & nd & 1,5 & 0,010 & nd & 0,08 & nd & nd \\
\hline
\end{tabular}

Tab. 1. Análisis elemental por fluorescencia de rayos X (\% en peso). 


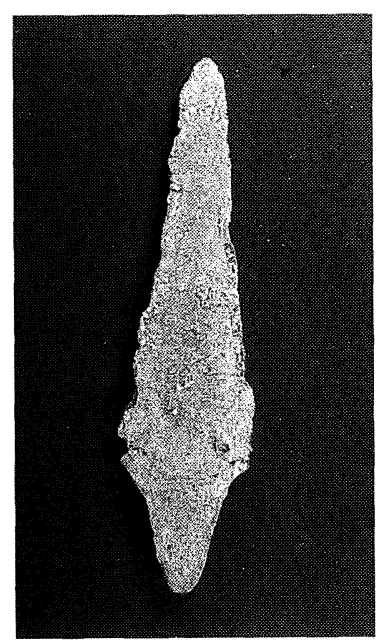

A

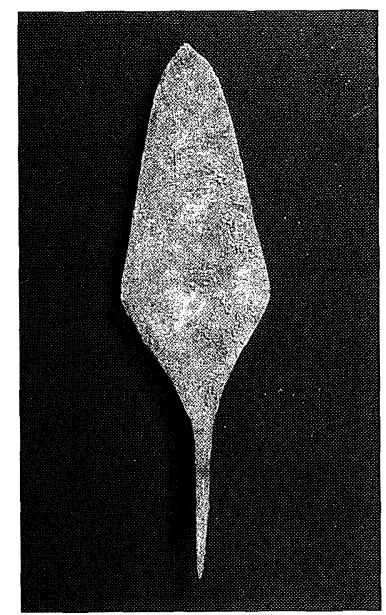

B

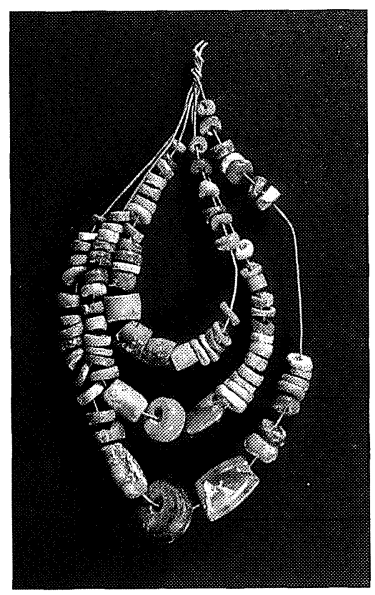

C

Lám. I. Materiales procedentes de la cueva artificial de Valle de las Higueras. Huecas. Toledo. A: Puñal de espigo campaniforme; B: Punta Palmela; C: Cuentas de collar de color verde. Fotos R. de Balbín.
Museo del Prado, que traduce un conjunto bastante homogéneo realizado en cobre, con tasas de arsénico entre el $0,8 \%$ y el $1,5 \%$, correspondiendo a los puñales el metal más arsenicado de esta serie. La mencionada homogeneidad que se concreta tambien en valores semejantes de impurezas de plata y antimonio, permite plantear una fuente de materia prima común

Si bien las evidencias para sostener una metalurgia local no son muchas, recordemos el mencionado plato de borde engrosado, procedente del poblado del Fontarrón. Tras un meticuloso rastreo con el microscopio electrónico de barrido, se pudo localizar un punto de escorificación con la composición porcentual siguiente:

$2,8 \mathrm{CuO} ; 0,5 \mathrm{MgO} ; 9,9 \mathrm{Al}_{2} \mathrm{O}_{3} ; 39,7 \mathrm{Si} \mathrm{O}_{2} ; 1,4$ $\mathrm{K}_{2} \mathrm{O} ; 2,6 \mathrm{CaO}$ y $43,1 \mathrm{FeO}$.

La existencia de metalurgia del cobre con evidencias de vasijas horno y objetos sencillos ha sido valorada por Blasco y Rovira (1993: 399) como la expresión de manufacturas locales basadas en afloramientos filonianos situados en la Sierra de Guadarrama, y, por tanto, como la constatación de una metalurgia local en el Tajo interior con expresiones tan claras como las documentadas en el poblado del Ventorro, Madrid (Harrison et alii, 1975).

Hay referencias sobre mineralizaciones de cobre en la provincia de Toledo (Montero et alii, 1990). Sectores próximos como Guadamur, Polán, Layos o, algo más abajo pero siempre siguiendo el curso de los afluentes del Tajo: Mora, Orgaz, Pulgar... etc., poseen pruebas de esta presencia.

El Tajo, se encuentra unos $10 \mathrm{~km}$ al Sur de Huecas y el Guadarrama tambien está muy próximo a nuestro yacimiento. Su situación respecto a las vías de comunicación es muy buena, como se observa en la notoria proximidad que tiene a la tradicional Cañada Segoviana, referencia que entendemos en el sentido ya expresado de la búsqueda de estos yacimientos de situaciones con fácil acceso y control de pasos (Bueno Ramírez, 1991; Bueno Ramírez et alii, 1999). No hay que olvidar que en la zona del Guadarrama se recogen yacimientos cupríferos en superficie (Blasco y Rovira, 1993).

Huecas se encuentra en las proximidades de Torrijos, por tanto en el sector que J. Muñoz (1977) denomina comarca de Torrijos, pero también participa de las características paisajísticas y geoló-gicas de la meseta de Toledo. Presenta relieves de cerros testigo con base caliza, como los que se conocen en otros términos del valle bajo del río Guadarrama, en Bargas y Yunclillos (Carrobles, 
1990: 34), aquí acompañados de valles de carácter aluvial.

Los indicios de una población neolítica que conectase con los datos que nos proporcionan los enterramientos del Castillejo son muy difusos en la provincia de Toledo y, hasta ahora, sólo se han localizado en yacimientos funerarios. Nos referimos, sobre todo, a los dólmenes (Bueno Ramírez, 1991; Bueno Ramírez y de Balbín Behrmann, 1996; Bueno Ramírez et alii, 1999). No obstante, evidencias como la señalada por E. de Álvaro (1987: 19) sobre un enterramiento en fosa con muchos individuos en San Martín de Pusa, Toledo o las publicadas por Villa y Rojas (1996) en Mesegar del Tajo, hacen albergar esperanzas acerca de las posibilidades de documentación que se abren para el futuro. La constatación de materiales neolíticos en la Comunidad de Madrid (Castañeda y González, 1996; Fernández-Posse, 1980), viene a ratificar la entidad cada vez más marcada del Neolítico interior .

El Calcolítico está mejor documentado, constituyendo la presencia de hábitats campaniformes, un hecho contrastado. Así en Layos o Mazambroz, o muy próximos a Huecas caso de Calaña, en Albarreal de Tajo (Rojas, 1988: 200) y en el mismo valle del Guadarrama: Yunclillos. Un trabajo posterior (Rojas y Rodríguez, 1990) señala la abundante presencia de cerámica Ciempozuelos en Toledo, desgraciadamente sin contexto. Más recientemente otros datos han venido a sumarse a este panorama del campaniforme toledano. Entre ellos destacan los procedentes del Cerro del Bú, con fechas asociadas a campaniforme marítimo: $3970 \pm 100 \mathrm{BP}$ y 3830 \pm 100 BP (Álvaro y Pereira 1990: 205).

Respecto a fuentes de materias prima próximas a los yacimientos que referimos, son destacables las extracciones de sílex que probablemente constituyeron un elemento de intercambio en momentos paralelos al desarrollo de estas poblaciones. Precisamente, el estudio y análisis de estas zonas de extracción constituirá uno de nuestros objetivos en un futuro próximo.

La riqueza más obvia de estas tierras es la agrícola. De hecho el valle en el que se sitúa el túmulo del Castillejo es especialmente rico para cultivos de trigo y cebada aún en la actualidad. Como se observa en el mapa de dedicación actual (Fig. 1), el valle del que hablamos es una zona de labor intensiva. La proximidad de una laguna que estuvo activa hasta épocas relativamente recientes, acrecienta las opciones agrícolas que hemos mencionado.
La ocupación neolítica y calcolítica de los yacimientos de Huecas parece responder a una explotación del territorio que daría como resultado buenos excedentes agrícolas. Sólo análisis detallados procedentes de la excavación en el área de hábitat nos permitirán saber algo más sobre esta dedicación agrícola que suponemos especializada en gramíneas y legumbres por las características del terreno y, desde luego, sobre el espectro ganadero del que nada sabemos. Las materias primas como el cobre o el sílex tienen posibilidades cercanas de fácil acceso y buena calidad. A ello deberíamos añadir, cuando las analíticas sean más explícitas, una más que probable explotación de sustancias colorantes. La situación de la población, próxima a una importante vía de paso, le permite controlar las redes de intercambio que se generaron entre las zonas interiores y el Atlántico en la época a la que nos referimos.

\section{METODOLOGÍA Y RESULTADOS DE LA PRIMERA CAMPAÑA DE EXCAVACIONES EN EL TÚMULO DEL CASTILLEJO DE HUECAS}

El túmulo del Castillejo de Huecas es una elevación, que destaca claramente en el terreno, de 26,50 $\mathrm{m}(\mathrm{E} / \mathrm{O}) \times 21,50 \mathrm{~m}(\mathrm{~N} / \mathrm{S})$, tanto por su altura -prácticamente $2 \mathrm{~m}$ - como por el color oscuro de la tierra que lo compone y que contrasta nítidamente con el barbecho circundante de color gris, casi blanco. Tiene un contorno oval, amesetado en la zona superior (Lám. II).

Nuestra primera tarea consistió en una limpieza de todo el perímetro tumular que se nos reveló como bastante amplio, y deforme en su zona central. Efectuada ésta, pudimos comprobar que no se

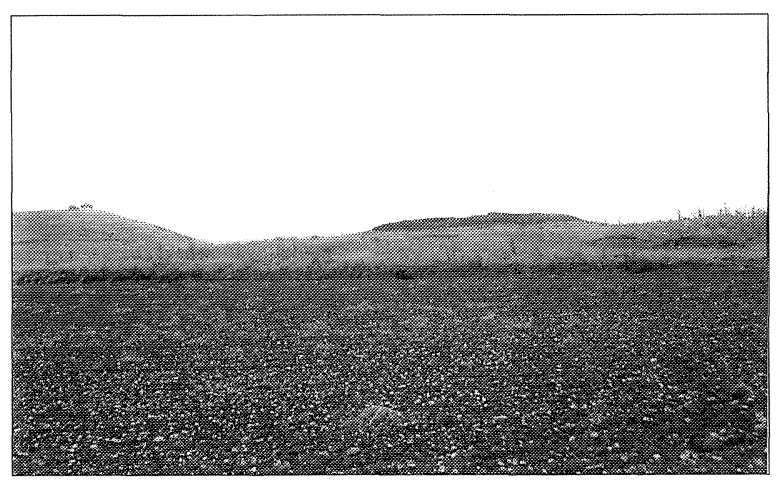

Lám. II. Vista del túmulo del Castillejo (Huecas, Toledo), desde el poblado del Fontarrón. Foto R. de Balbín. 
trataba de un monumento dolménico, como en un principio nos había parecido, o al menos no respondía a la forma tradicional de los túmulos dolménicos de la provincia, cuya excavación ha sido realizada por nosotros (Bueno Ramírez, 1990, 1991; Bueno Ramírez y de Balbín Behrmann, 1996; Bueno Ramírez et alii 1998).

Situamos el P. 0 en una piedra caliza de mediana envergadura localizada en la zona superior, junto al lugar donde J.M. Rojas y R. Villa habían realizado su corte en 1997, y trazamos dos cortes longitudinales abarcando la zona central y el contorno tumular.

El Corte 1 queda orientado S. E/N. O y mide 14 $\mathrm{m} \times 4 \mathrm{~m}$. El Corte 2, perpendicular al anterior, mide $8,5 \mathrm{~m}$ en sentido N/S y $4 \mathrm{~m}$ E/O. Nuestro sistema de excavación sigue las tradicionales coordenadas de Wheeler, con delimitaciones internas de $1 \mathrm{~m}$, que se indican con letras. Las piezas se sitúan en plano y en cotas respecto al P. 0, numerándose correlativamente y se empaquetan con una ficha propia, en la que se refleja la información mencionada. Los huesos se recuperan de la misma manera.

El túmulo está compuesto por piedra caliza de tamaño pequeño, mezclada con una tierra de color oscuro que no procede del lugar. Esta tierra se ha acarreado desde el valle próximo y posee en su interior muchos restos líticos de aspecto Paleolítico Inferior y Medio. En amplias zonas del valle, R. Félix ha comprobado la existencia de estas piezas, huella de una importante ocupación paleolítica que está comenzando a constatarse en otros sectores de

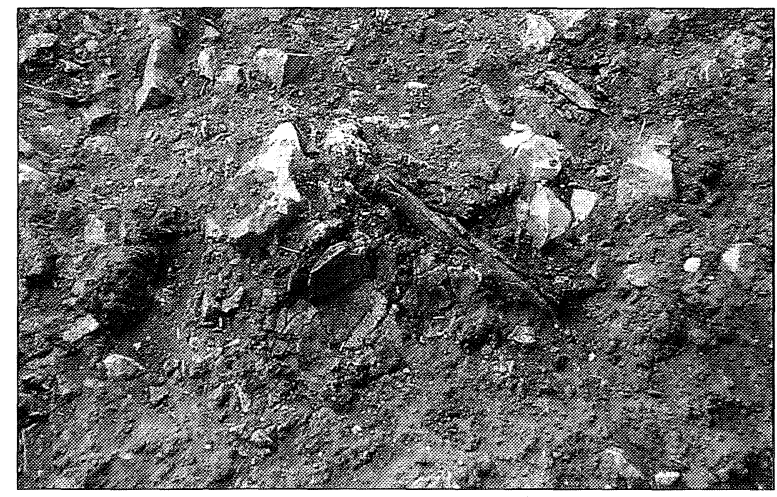

Lám. III. Detalle de la imbricación entre los huesos humanos y las piedras del túmulo en el Nivel I. Túmulo del Castillejo (Huecas, Toledo). Foto R. de Balbín.

la provincia de Toledo (Bueno Ramírez et alii, 1999: 108).

Tanto las piedras que hemos mencionado como los primeros hallazgos se localizan practicamente en superficie (Lám. III), como los restos de una coraza tumular que se ha hundido sobre los enterramientos, lo que hace que encontremos huesos y piedras en una amalgama, junto con las primeras evidencias de ajuar (Fig. 2).

En el sector Este del Corte 1, la caliza aflora a $-0,80 \mathrm{~m}$ del P. 0 y sobre ella y aprovechando su altura, ya de por sí destacada en el paisaje, se ha comenzado a rellenar con esa tierra más oscura que antes mencionábamos, entre la cual aparecen algunas evidencias líticas paleolíticas, además de restos cerámicos y líticos contemporáneos a los enterra-

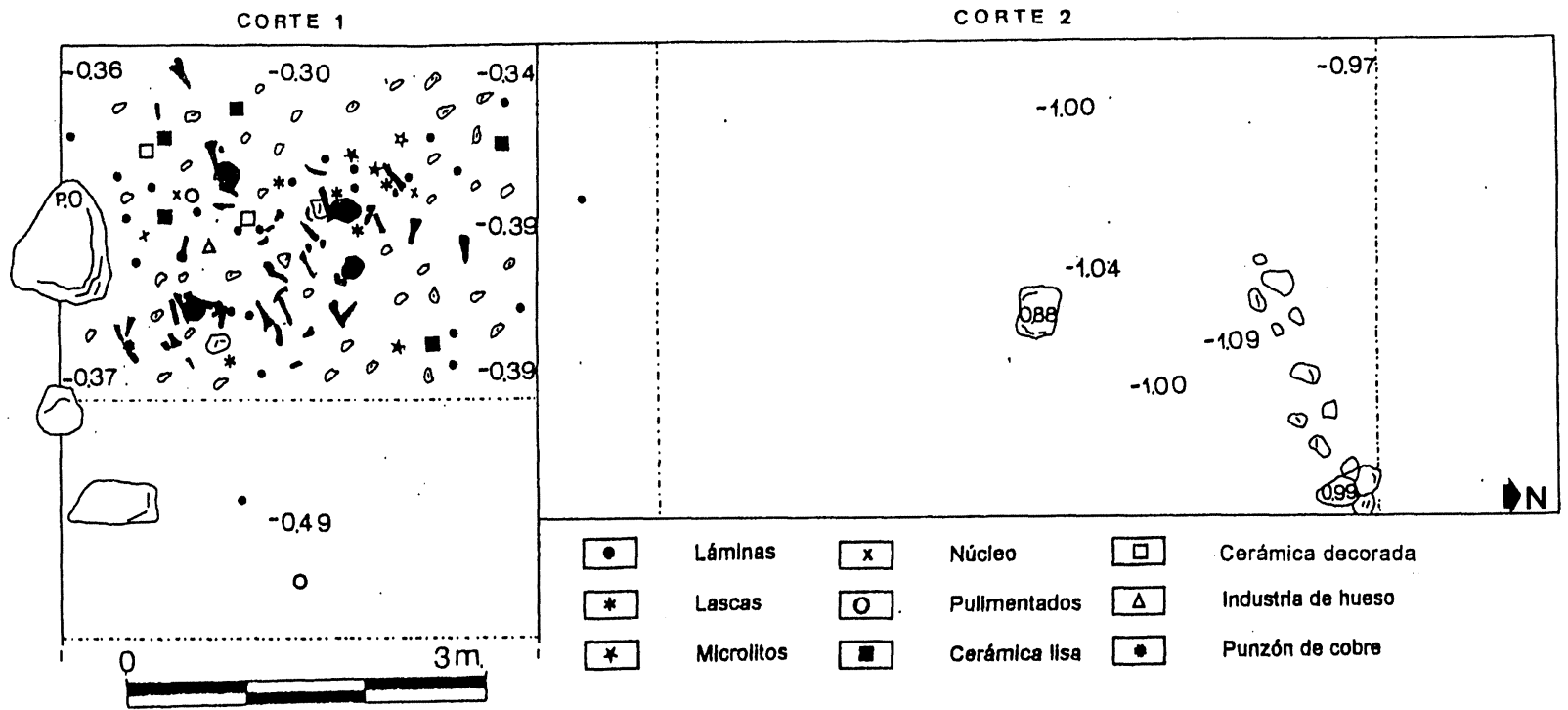

Fig. 2. Túmulo del Castillejo (Huecas, Toledo). Planta con la situación de los huesos y los hallazgos de Nivel I en corte 1.

T. P., 56, n. ${ }^{\circ} 2,1999$ 


\section{CORTE 1}

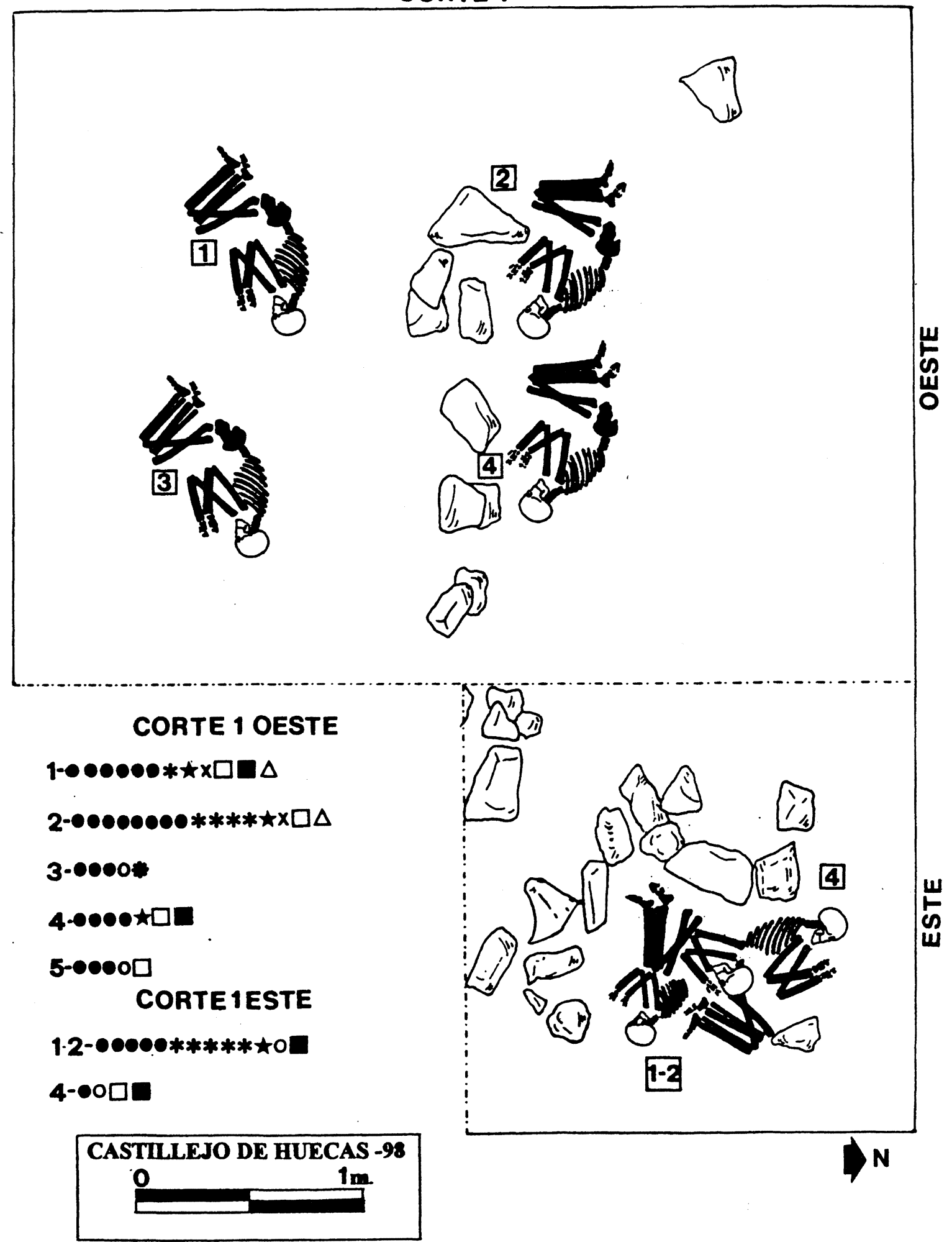

Fig. 3. Túmulo del Castillejo (Huecas, Toledo). Reconstrucción de la situación de los muertos y del ajuar que se les puede adjudicar. Los símbolos utilizados son los mismos que los de la figura 2. 
mientos. Estos últimos se han incluido en el relleno de modo intencional. El relleno descrito alcanza hasta la cota - 0,49 , en la que se han depositado los enterramientos que describiremos a continuación.

Esto podemos deducir de lo que hoy se conserva: no sería de extrañar que la altura original fuese mayor pues los agentes erosivos han debido jugar un papel importante.

En la zona más alta afloran restos humanos que se encuentran a una cota ligeramente inferior en la zona Este. En este sector comenzamos a delimitar unas piedras de mayor tamaño en su lateral Norte e inmediatamente tambien, restos humanos. Esta diferencia nos llevó a separar los restos como nivel II. Así la parte más alta de los enterramientos se denominará Corte 1 Oeste, Nivel I y la más baja, Corte 1 Este, Nivel II.

Los restos humanos del Nivel I (Corte1 Oeste) muestran una disposición que argumenta la existencia de, al menos, cuatro individuos colocados en posición encogida. Los restos del cráneo se asocian siempre al hueso largo del brazo. A estos cuatro individuos habría que sumar un quinto, exhumado en la excavación de 1997. La posición que proponemos, y con ella la adjudicación de los ajuares, es solo una hipótesis que habrá de ser contrastada con los datos de la campaña de 1999 (Fig. 3).

Hemos numerado los individuos empezando por el situado más al Oeste y de izquierda a derecha. Los restos se encuentran en estudio por el Dr. F. Etxeberría, por lo que no podemos concretar sexos y edades. No obstante, en lo que nosotros podemos observar, se trata de restos de adultos.

Al Muerto 1 se asocian un punzón de hueso, seis o siete láminas, un microlito, un núcleo, una lasca y cerámica lisa e incisa.

Al Muerto 2, ocho o nueve láminas, un microlito, un núcleo, cuatro lascas, una arandela o cuenta de hueso y cerámica lisa. Destaca como en el anterior, la presencia de lascas que sugieren una talla in situ.

Al Muerto 3, tres láminas, dos de ellas situadas sobre el esternón, un punzón de cobre (Fig. 4A) y un fragmento de piedra pulida (Fig. 4B). No nos extrañaría por la posición de este individuo que parte de los materiales extraídos por nuestros compañeros J.M. Rojas y R. Villa hubiesen pertenecido a su ajuar. Como en los anteriores, hay abundante presencia de esquirlas de sílex que creemos se deben a que se ha tallado in situ.

El objeto de piedra pulida es de difícil identificación pues está fragmentado, pero de alguna ma-
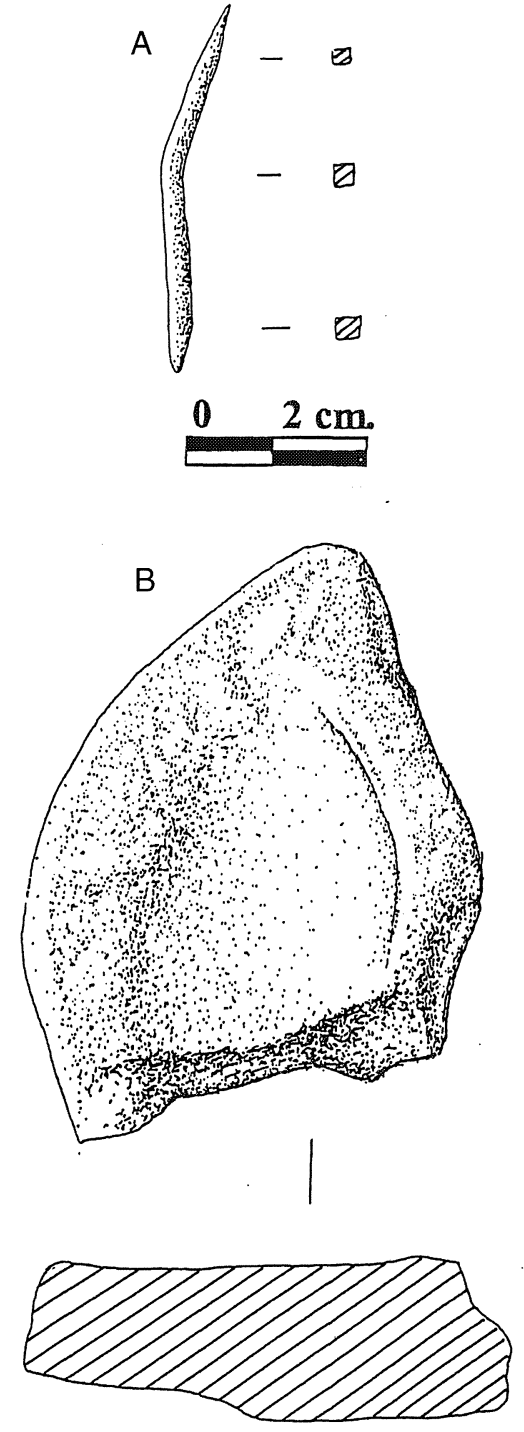

Fig. 4. Túmulo del Castillejo (Huecas, Toledo). Muerto 3, nivel I, Corte 1 Oeste. A: Punzón de cobre; B: Fragmento de piedra pulida.

nera recuerda piezas con depresión central como las documentadas por nosotros en el toledano dolmen de la Estrella (Bueno Ramírez, 1991: 82).

$\mathrm{Al}$ Muerto 4, se asocian cuatro láminas, un microlito, cerámica incisa y cerámica lisa.

El Muerto 5 sería el detectado en la campaña de 1997. No sabemos su situación exacta, pero debía encontrarse entre Ic y Corte 1 Este. Nuestros compañeros nos entregaron los restos óseos y los materiales. De ello podemos deducir que se trata de un individuo prácticamente completo, acompañado de laminitas, cerámica lisa y un fragmento de escobillada. 


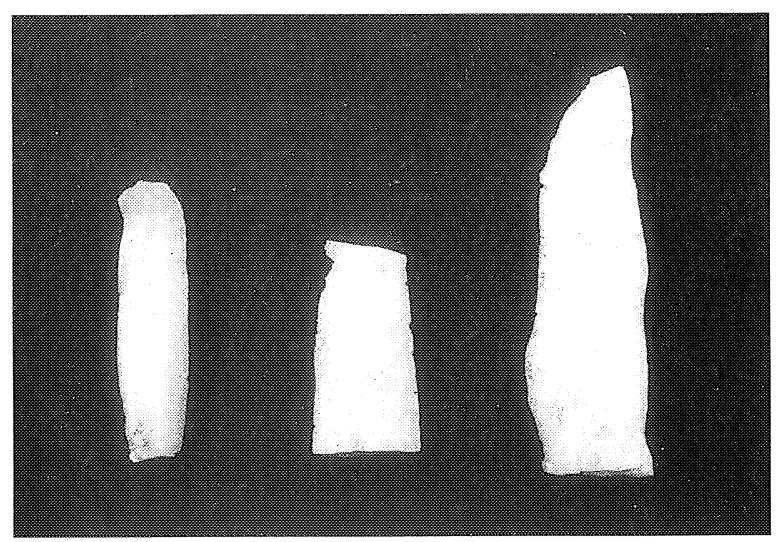

A

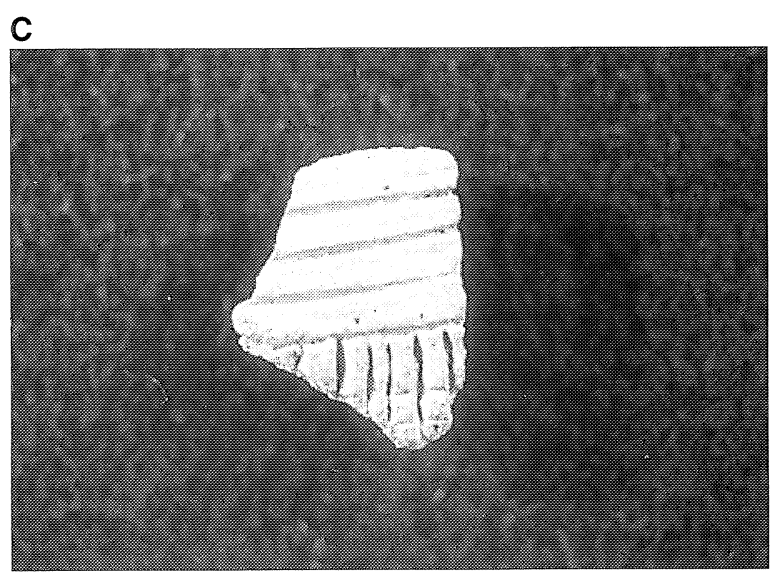

Se observa una cierta "estandarización”. Todos los individuos portan láminas (Lám. IV A) y cerámica lisa, cuatro un microlito (Lám. IV B), tres restos de talla y cerámica decorada (Lám. IV C), dos un punzón de hueso (Lám. IV D). La presencia del punzón de metal desentona claramente en un conjunto de fuertes reminiscencias antiguas que, por otra parte no presenta ninguna de los elementos "estandar" de los ajuares campaniformes. La situación de los restos en la superficie actual y la proximidad del poblado del Fontarrón explicarían una posible frecuentación campaniforme del lugar.

La presencia de microlitos y la ausencia de puntas de flecha, junto con la abundancia de laminitas y restos de talla, siempre en sílex, punzones de hueso, alguna cerámica lisa de borde indicado y algún fragmento decorado, reitera el ajuar documentado por nosotros en el dolmen de Azután (Bueno Ramírez, 1991), ratificando la conexión cultural con el megalitismo y proponiendo el desarrollo de este horizonte de enterramientos en el IV milenio a.C.

Para este nivel poseemos una fecha realizada por el procedimiento tradicional, sobre huesos del

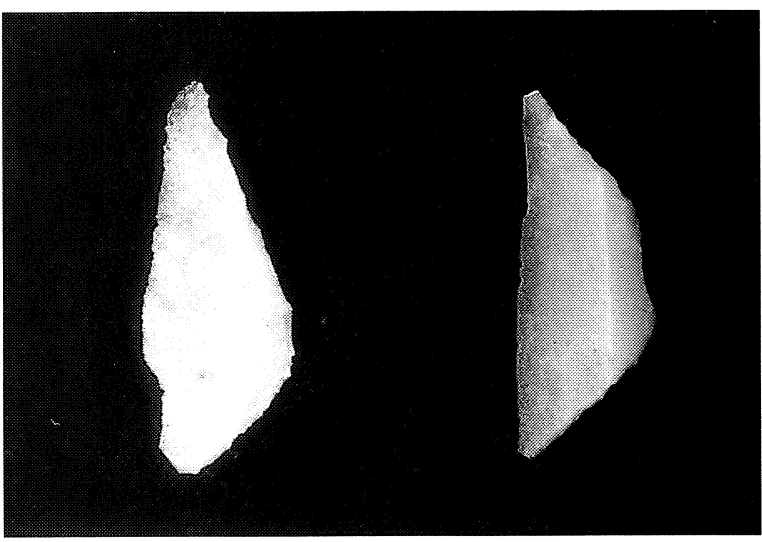

B

D

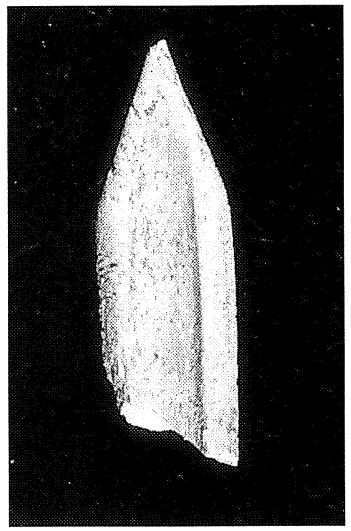

Lám. IV. Túmulo del Castillejo (Huecas, Toledo). Ajuares de los muertos de Cortel Oeste. A: Láminas; B: Microlitos; C: Cerámica incisa; D: Punzón de hueso. Muerto 1. Fotos R. de Balbín.

Muerto 4 de $5710 \pm 150$ BP (Beta 132917). La calibración a 1 sigma es de 4720 a 4365 BC, con el $68 \%$ de probabilidades. En el análisis propuesto por el laboratorio, la fecha probable es $4535 \mathrm{Cal} \mathrm{BC}$.

El punzón de cobre de sección cuadrangular remite a evidencias de un Calcolítico pleno, de las cuales disponemos de muchos ejemplos en la Península (Pérez Arrondo y López de Calle, 1986), alguno de ellos muy cercanos, como el del Cerro del Bú (Rovira et alii, 1997: 377) o en la provincia de Madrid (Martínez Navarrete, 1984). Teniendo en cuenta los enterramientos ya descritos de Valle de las Higueras con metal y campaniforme, nuestro punzón no desentona en la ocupación calcolítica del Valle, como señalábamos más arriba.

En esta zona no pudimos profundizar más, pero sí en el sector "Corte 1 Este", a mayor profundidad que los restos descritos. En él se delimitan inmediatamente dos partes: la Sur con escasos y dispersos restos óseos acompañados de algún material y la Norte, en la que aparecen piedras de tamaño mediano y muy pronto importantes restos humanos.

En Corte 1 Este, sector Sur, localizamos un mi- 


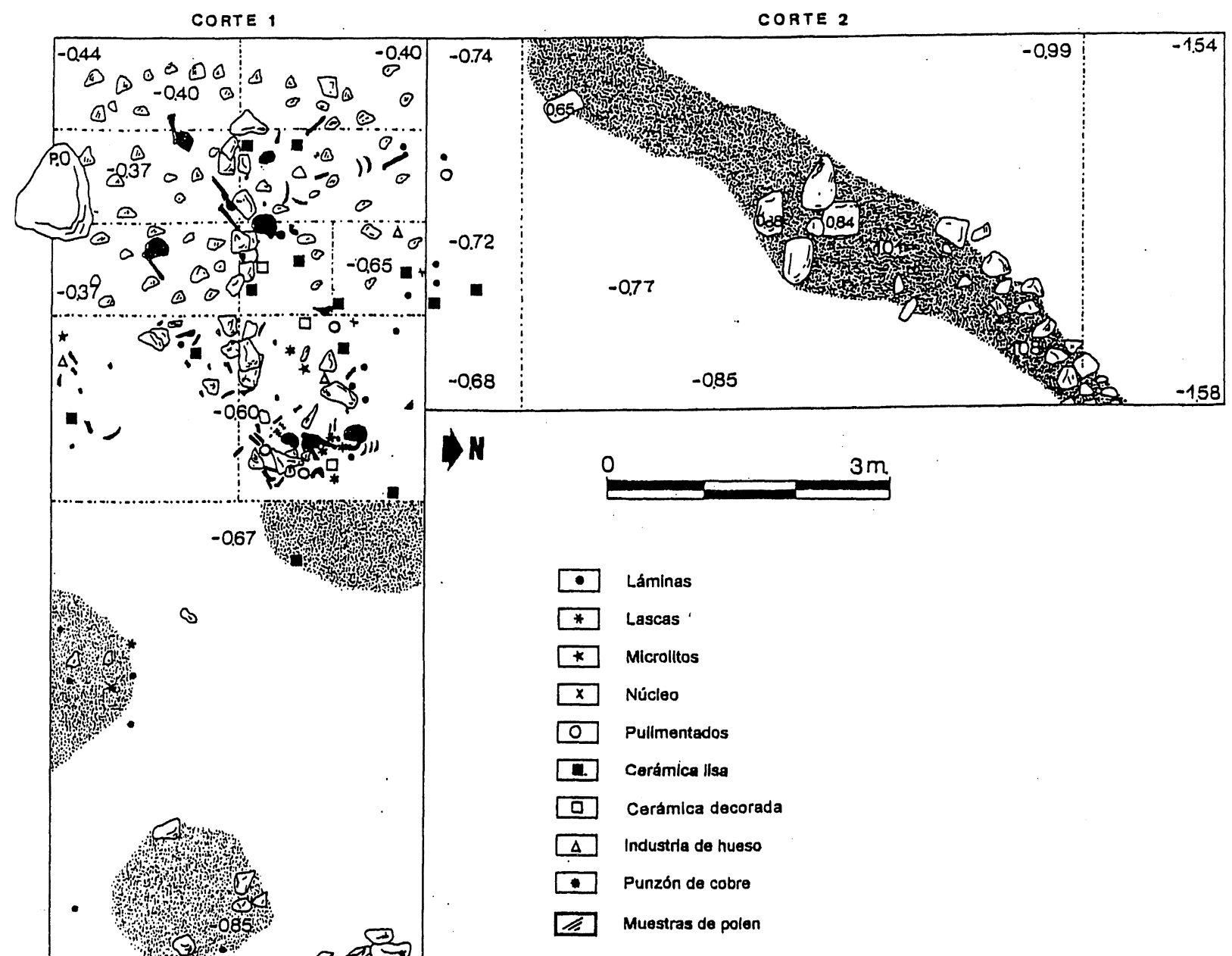

Fig. 5. Túmulo del Castillejo (Huecas, Toledo). Cotas de los hallazgos de nivel II, Corte 1. Se aprecia tambien la subestructura de corte 2 y restos de cabañas de corte 1.

crolito, dos punzones de hueso y una hoja apuntada. Las características tipológicas del material, especialmente la presencia de punzones de hueso como en el Muerto 1, o la de un microlito como en los Muertos 1, 2 y 4, nos permiten sugerir que nos encontramos ante los restos de otro depósito mortuorio. Quizá había aquí otro cadáver (posible Muerto 6) aunque no descartamos que éste hubie- se pertenecido al Muerto 5, excavado por nuestros compañeros.

El mal tiempo hizo su aparición y como nos preocupaba no poder documentar todas las cuadrículas que teníamos abiertas, optamos por profundizar sólo en el lateral Norte de Ic y en el sector Norte del Corte 1 Este (Fig. 5).

En Corte 1 Este, sector Norte, al interior de las 


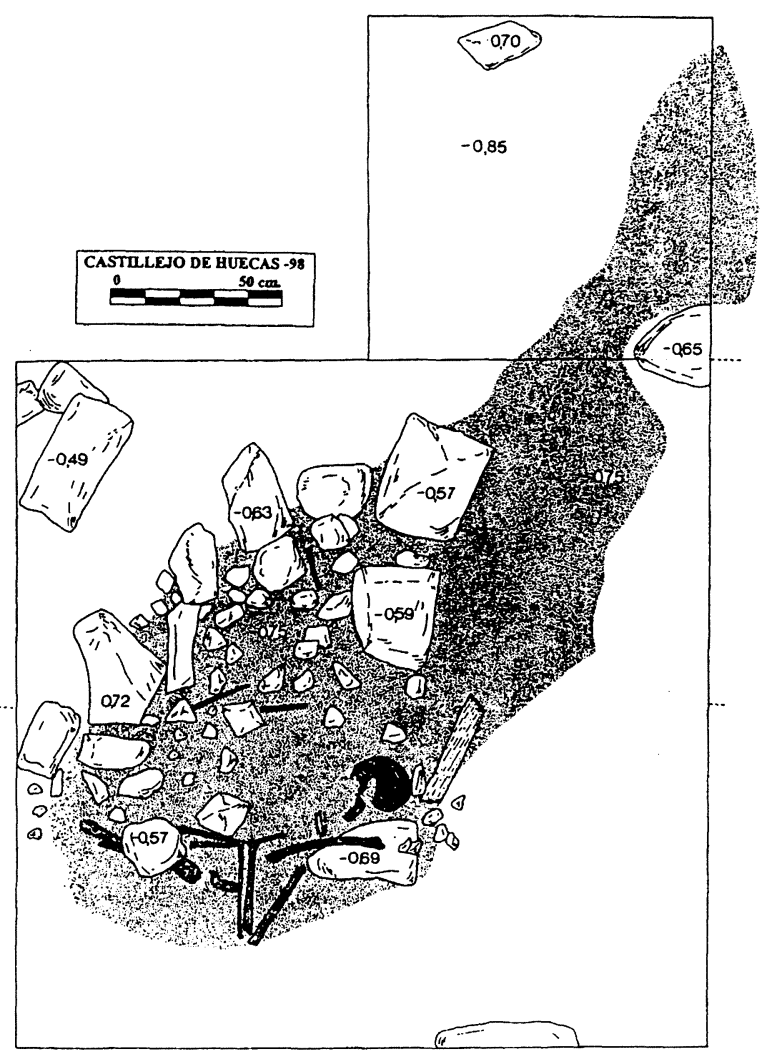

Fig. 6. Túmulo del Castillejo (Huecas, Toledo). Cotas de nivel II en corte 1 Este en el uso inicial de la "plataforma" y detalle de la extensión del "suelo"preparado marcado en oscuro.

mencionadas piedras, comienzan a delimitarse en torno a $-0,54 \mathrm{~m}$ del P. 0 restos óseos, ahora dispuestos de un modo diferente al que hemos descrito en el Nivel I: están literalmente encajados en una estructura de aspecto paracircular de $1 \mathrm{~m}$ de diámetro (Fig. 6). Por tanto, no aparecen depositados en un espacio amplio como los anteriores.

Los primeros son un cráneo completo con órbitas supraciliares hacia el Oeste junto al cual y, concretamente, pegados a sus fosas nasales se aprecian las falanges de una mano; bajo el cráneo, un hueso largo. Pocos centímetros a la izquierda de este individuo que interpretamos como femenino, a la espera de los resultados del estudio antropológico, aparecen los restos de un parietal infantil. Algunos huesos infantiles dispersos quedan documentados también en la zona Oeste de esta estructura a la que denominaremos "plataforma". Junto a la mujer y el niño, una mandíbula en la parte Este del Corte que interpretamos como perteneciente a un individuo adulto masculino del que no localizamos más restos (Lám. V). Su ajuar es indiferenciable por la

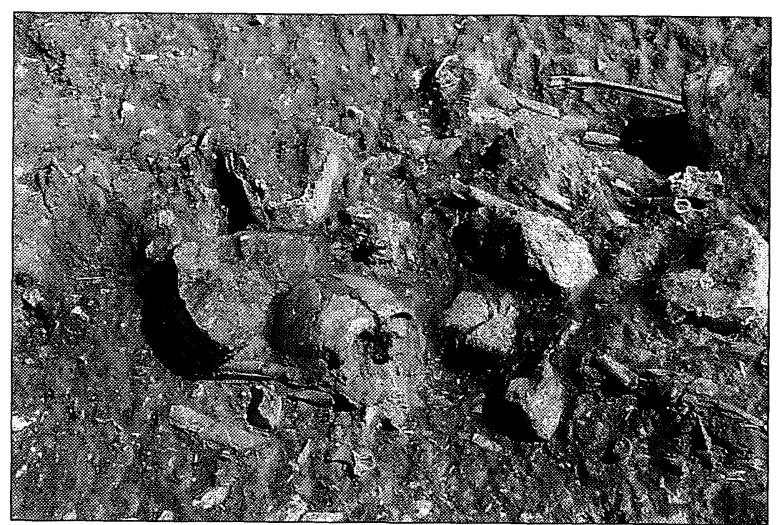

Lám. V. Detalle de los hallagos de restos humanos del nivel II del corte 1 Este. Túmulo del Castillejo (Huecas, Toledo). Foto R. de Balbín.

posición de proximidad que mantienen los restos.

A estos restos humanos podemos asociar cinco láminas, un microlito, cinco lascas, un machacador y una cerámica decorada con incisiones horizontales y verticales. Es decir un ajuar bastante similar a los que hemos descritos para el Nivel I, en este caso, interpretable como una ofrenda colectiva.

La intersección de Corte 1 Este y Corte 2 parece haber sufrido alguna remoción, pues la tierra está suelta, no compacta como pudimos comprobar en las zonas más intactas de Corte 1 Este excavadas en la campaña de 1999. No obstante, esta remoción ha afectado muy parcialmente a los restos descritos.

Una vez delimitados, excavados, dibujados y fotografiados, los levantamos y localizamos los de un individuo completo en posición encogida con el cráneo al Sur del de la mujer y el cuerpo por debajo de las inhumaciones descritas (Lám. VI).

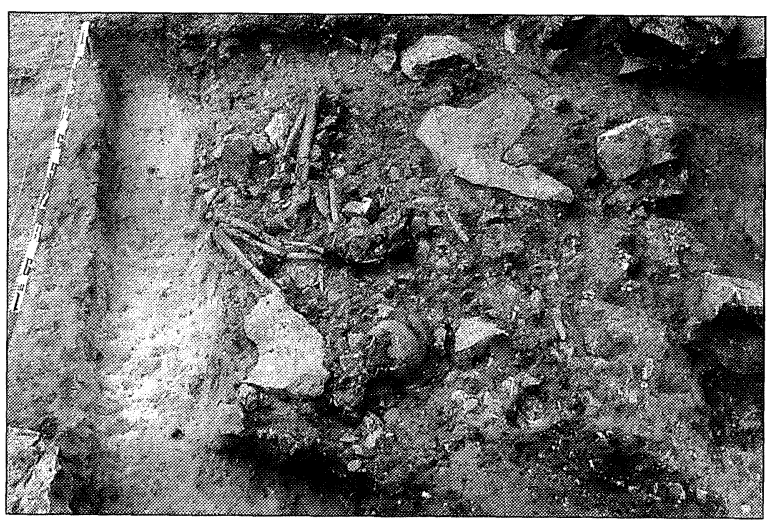

Lám.VI. Plataforma inicial de enterramientos correspondiente al nivel II del corte 1 Este. Túmulo del Castillejo (Huecas, Toledo). Foto R. de Balbín. 


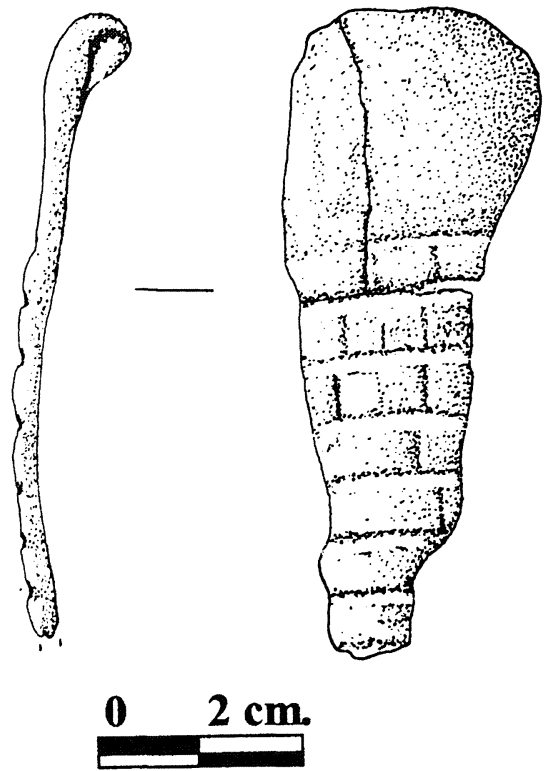

Fig. 7. Túmulo del Castillejo (Huecas, Toledo). Mango en hueso localizado en corte 1 , cuadrícula Ic.

La limpieza de este enterramiento nos revela que la antedicha "plataforma" se asienta sobre un suelo preparado de color oscuro, por lo que creemos contiene restos de materia orgánica, quizá madera por el aspecto fibrilar que presentaba.

A esta cota $-0,67 \mathrm{~m} /-0,70 \mathrm{~m}$ del P. $0-$ se localizan los siguientes materiales que interpretamos pertenecen al depósito del individuo que acabamos de describir o, cuando menos, fueron depositados a la vez que él. Se trata de una lámina, un machacador vertical con restos de color rojo, dos fragmentos de cerámica decorada, una de ellas con incisiones e impresiones y otra, con zig-zags incisos, además de un borde de cerámica lisa.

En el reducido espacio que hemos denominado "plataforma" hay cuatro enterramientos y la posibilidad de que los análisis antropológicos nos indiquen alguno más. No nos resistimos a sugerir que las cinco láminas y las cinco lascas arriba mencionadas indiquen el ajuar de cinco individuos. A ellas habría que sumar la lámina del último cadáver, el primero en ser depositado.

Por tanto, nos parece que queda claro que tanto estructuralmente como socialmente, el significado de los enterramientos descritos en Nivel I y en $\mathrm{Ni}$ vel II es nítidamente distinto, pese a que los materiales genéricamente podrían ser contemporáneos.

El corte en profundidad que planteamos en Corte 1 Este tambien afectó a la zona más próxima de nivel I. En dicho cuadro localizamos tierra más suelta, con materiales dispersos y escasos y, en la base del mismo la continuación de la preparación de color oscuro y textura sólida a la que hemos denominado "suelo"en la plataforma. Esta se aprecia exclusivamente en la parte derecha del corte. En la izquierda, en el cuadrante Noroeste, apareció un fragmento de mango tallado de hueso que numeramos como hallazgo 100, de gran interés (Fig. 7).

Estos mangos han sido localizados en enterramientos de la Meseta Norte y de la Rioja (Delibes et alii, 1987)y se interpretan como mangos de espátulas. Un reciente análisis (Mujika, 1998) destaca que se realizan sobre tibias de Capra/Ovis, aunque dada la transformación del original, es dífícil asegurar si es uno u otro animal. Las piezas meseteñas tienden a presentar formas de menor anchura que la que nosotros hemos documentado en Huecas que podría ponerse mejor en relación con las de Gurpide (Pérez Arrondo y López de Calle, 1986: 60). Un objeto similar, que también posee acanaladuras en la zona superior, procede de Kurtzebide, hallazgo que nos interesa por la descripción que realiza Vegas (1981) como enterramiento megalítico sin estructuras reconocibles.

G. Delibes ha tenido la amabilidad de comunicarnos que en las recientes excavaciones de la cueva de la Vaquera, llevadas a cabo por un equipo de la Universidad de Valladolid, se ha localizado una pieza semejante en los niveles de Neolítico final/ transición Calcolítico. Otra comunicación personal, esta vez de C. Barrio, nos indica la presencia de estos mangos decorados en un enterramiento colectivo de Villanueva de la Fuente (Ciudad Real). Todos estos datos abogan por una dispersión mayor de estas piezas que la que se proponía a finales de los años 80 (Delibes et alii, 1987: 190).

Para completar nuestra información sobre la forma y potencia del túmulo y sobre la extensión de los enterramientos en la cota más alta del mismo, marcamos otro Corte perpendicular al primero, al que denominamos Corte 2.

Nuestra primera observación es que en el primer metro de este Corte (2A), no localizamos ni un sólo resto humano, luego podemos afirmar que en este lado se agrupan claramente en la zona más alta del túmulo. Sólo aparecen algunos fragmentos de cerámica y de sílex y el mismo relleno que hemos verificado en otros sectores del túmulo: piedra pequeña asociada a tierra oscura que contiene evidencias paleolíticas.

La zona central del Corte 2 dibuja, tras el relleno ya mencionado, una estructura en la que aparecen

T. P., 56, n. ${ }^{\circ} 2,1999$ 


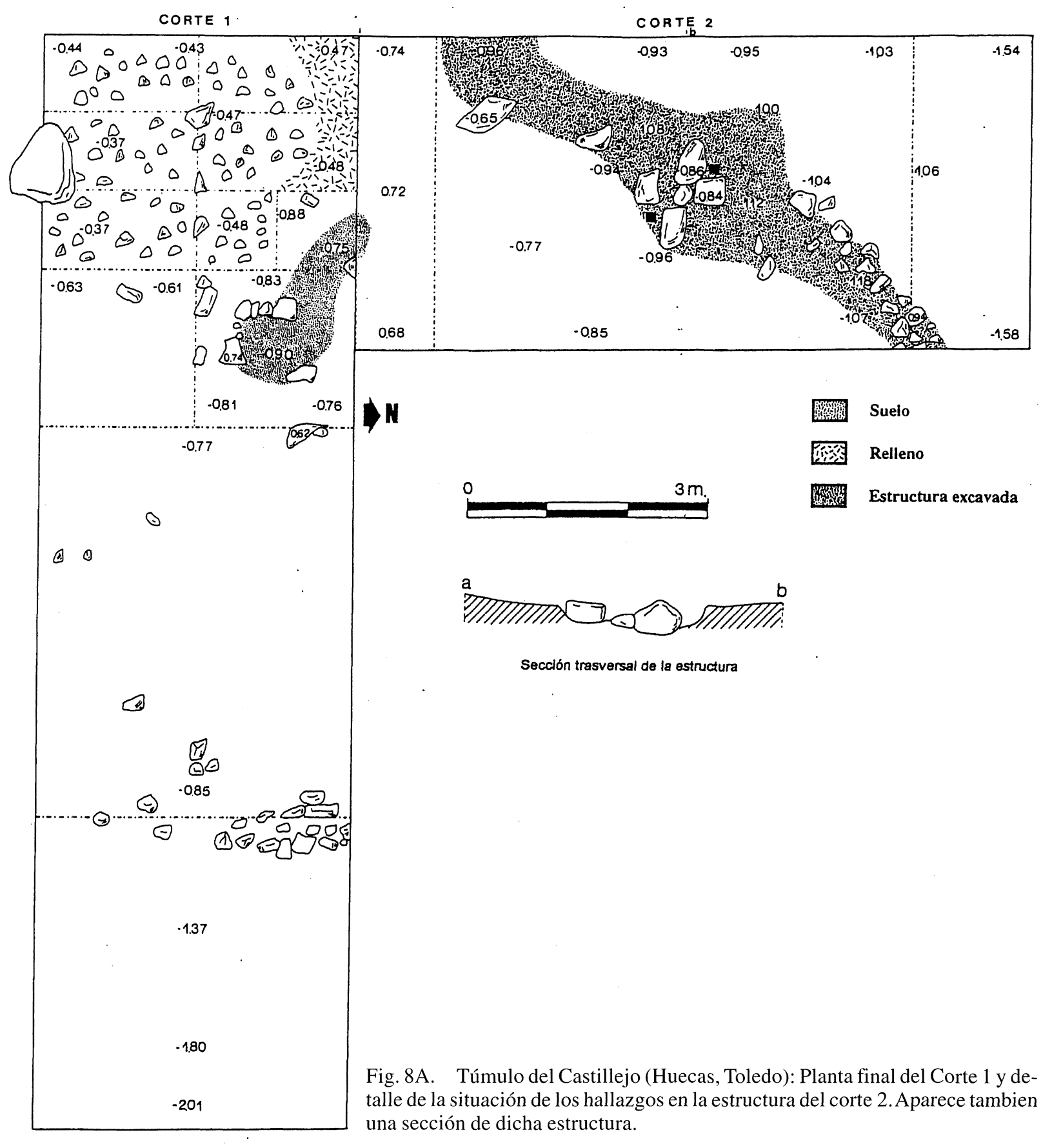

cuatro piedras -dos de sílex y dos de caliza- con claras huellas de fuego y tamaño destacable. Toda ella ha sido excavada en la caliza, como se aprecia en el perfil que adjuntamos (Fig. 8 A). Hay restos de materia orgánica que nos permiten sospechar de la existencia de más evidencias, pero cuya excavación dejamos para la próxima campaña. De esta cabaña procede una fecha AMS realizada por
Beta Analytic sobre pequeños restos de carbón: $4930 \pm 40$ BP (Beta-132915). La fecha calibrada que propone el laboratorio es 3695 Cal BC (5645 Cal BP).

La interpretamos como una cabaña en la que quizá se realizó algún trabajo artesanal especializado en el que el fuego jugaba un papel importante. (Lám. VII). 


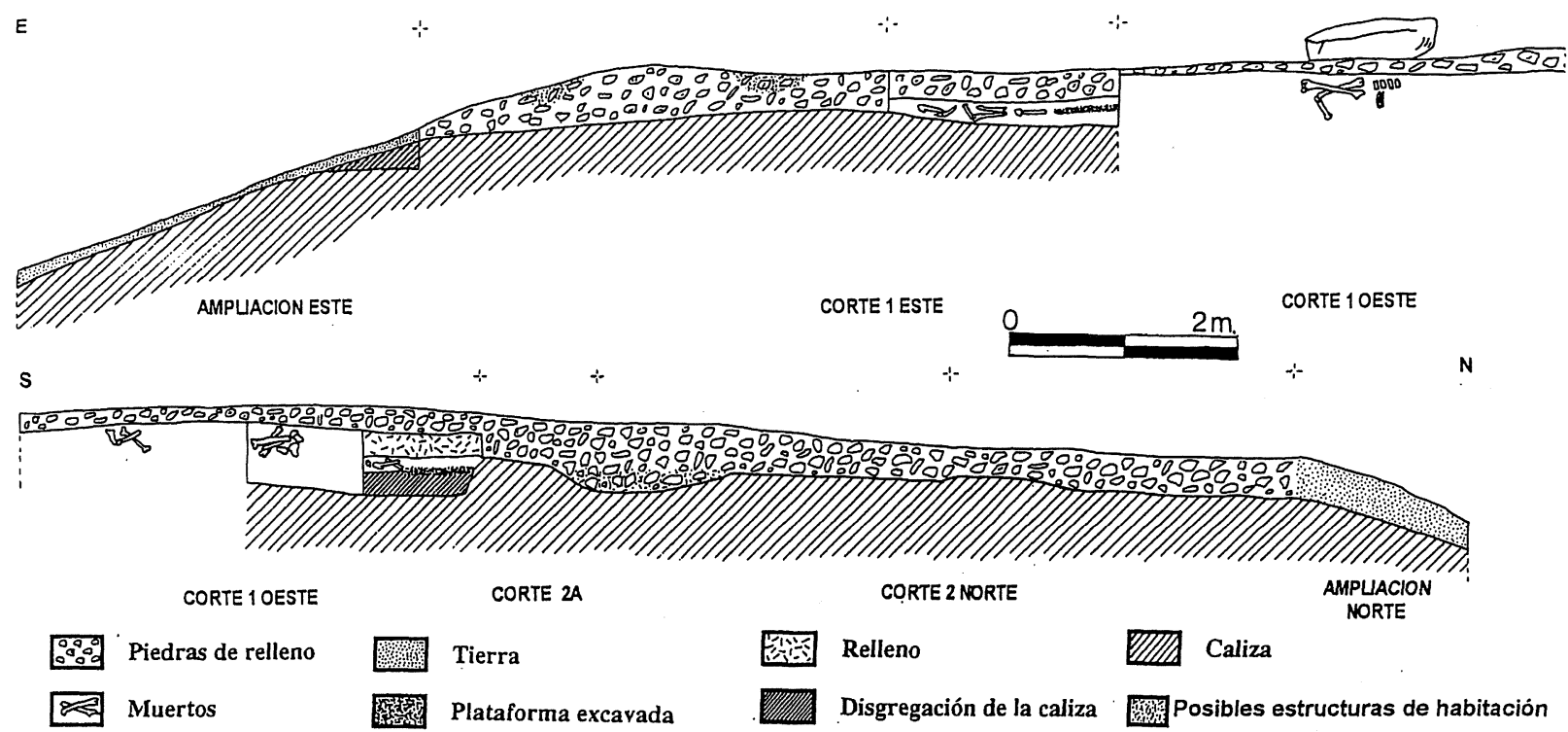

Fig. 8B. Secciones del túmulo del Castillejo con los datos obtenidos en la campaña de excavaciones de 1998.

Sobre la probabilidad de que se hubiese obtenido colorante a partir de óxidos de hierro, el argumento podría ser: la zona central tenía un fuego delimitado por las cuatro piedras mencionadas, en el que se calentaba agua en vasijas para incorporar hematites machacadas en polvo y obtener por fin una sustancia colorante de buena calidad. Algunas piezas de la excavación tienen restos de color como el punzón de hueso de Ib o el machacador vertical, asociado a los enterramientos del Nivel II.

La actividad de realización de colorante a partir de hematites está documentada arqueológicamente en la Península en un único yacimiento. Se trata del poblado de la Edad del Bronce delAcequión, en Albacete. M. Fernández-Miranda, M. ${ }^{2} D$. Fernán-

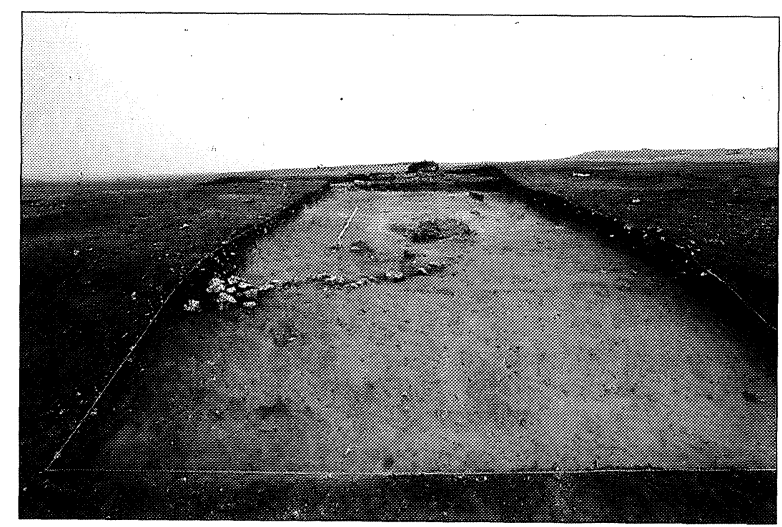

Lám. VII. Estructura localizada en corte 2. Túmulo del Castillejo (Huecas. Toledo). Foto R. de Balbín
dez-Posse y C. Martín (1990) recogen la existencia de una cabaña con restos de óxido de hierro asociados a la tintura de tejidos. Éste no es nuestro caso pero, como decíamos antes, es la única referencia arqueológica de fabricación de hematites como colorante.

Presencia de hematites en bruto, como la nuestra se ha detectado en el monumento megalítico de Eira Cavada (Gonçalves, 1989: 67) datable en el Calcolítico.

Los restos más dispersos de posibles áreas de habitación en el Corte 1 contribuyen a que planteemos que el túmulo del Castillejo refleja una secuencia habitación/necrópolis al estilo de otras que están comenzando a constatarse en la Meseta Norte (Delibes y Zapatero, 1996).

\section{MEGALITISMO CON Y SIN ESTRUCTURAS MEGALÍTICAS}

El túmulo del Castillejo plantea una serie de cuestiones de gran interés para comprender la dinámica de los enterramientos neolíticos y calcolíticos en el interior de la Península.

La sección que adjuntamos nos describe una elevación artificial de envergadura notoria que destaca especialmente en su entorno (Fig. 8 B). Está situada en un lugar central de un valle con grandes potencialidades agrícolas. Su volumen y su color contribuyen a su visualización desde todos los puntos del valle. 
Se encuentra al borde de una antigua laguna y en las proximidades del poblado del Fontarrón que creemos se habitó en momentos contemporáneos o muy próximos al uso del monumento funerario, aunque habrá que documentarlo mediante una excavación arqueológica. La reconstrucción visual de un poblado desde el que se contemplaría la laguna y destacando sobre ella el oscuro túmulo en el que se enterraban sus antepasados es una parte que no debemos olvidar en la interpretación de estas inhumaciones.

Tenemos documentados otros enterramientos en el entorno que nos permiten deducir la variedad de los mismos en un Calcolítico pleno al parecer de gran vigor, que indica una población continuada en el mismo valle, asentada por lo menos desde el IV milenio a.C., en fechas sin calibrar.

Sobre esta elevación se realizaron diversas estructuras de forma paracircular, entre las que destaca la localizada en el Corte 2. Su funcionalidad ha sido discutida en párrafos anteriores. La "Cabaña" descrita, más las perceptibles en el Corte 1 forman un núcleo habitacional adaptado al relieve del afloramiento calizo, más notorio en su vertiente Este. En un momento determinado, la estructura del Corte 2, junto con los restos mencionados en el Corte 1 , fue arrasada y sobre ellas se distribuyó un relleno de tierra negra, probablemente tomada del valle próximo a tenor de los materiales paleolíticos que contiene. Este arrasamiento es más notorio en Corte 1 que en Corte 2.

En la zona más alta, que no coincide exactamente con el centro del túmulo, pero sí con la mayor concentración de restos habitacionales por lo que hemos podido comprobar en la campaña de 1999 , se situaron los enterramientos.

Con orientación Este, se preparó un suelo con tierras de carácter orgánico, se delimitó un contorno más o menos circular con piedras calizas de tendencia plana y tamaño entre $30 \mathrm{~cm}$ y $40 \mathrm{~cm}$ y comenzaron a depositarse los restos. Primero un individuo completo, sobre y junto a él, una mujer acoplada al espacio como un paquete de huesos que significa una manipulación del cadáver, según la cual, los ligamentos son rotos y el total del cuerpo se ata fuertemente. Junto a ella, restos de un niño y posibles restos de otro adulto. Es pues, un espacio reducido en el que se han depositado varios cadáveres aparentemente en conjunto, dado lo imbricado de su conexión. Se trata de un auténtico enterramiento colectivo con fuertes aires de organización familiar. No descartamos que junto a inhumados completos, se incluyesen restos más antiguos procedentes de enterramientos anteriores.

Esto explicaría la conexión anatómica evidente de algunos de los descritos y la presencia de osamentas sueltas. Los materiales que aparecen con estos enterramientos se depositaron en conjunto.

El relleno de piedras medianas y pequeñas que tenía la estructura, indica que ésta tuvo una relativa altura inicial, posiblemente a modo de pequeño túmulo.

Los enterramientos de nivel I se han situado en cotas ligeramente superiores y fueron cubiertos completamente por piedras pequeñas. No nos extrañaría que sobre éstas se hubieran depositado piezas mayores desaparecidas con el tiempo, como podemos sospechar sucedió en la fosa de la Atalayuela (Barandiaran, 1978: 384), aunque sea de momentos posteriores y como está constatado en enterramientos similares franceses (Loison, 1998: 202). Acerca de la presencia de estas piedras tenemos constancia por algunos restos sueltos sobre el túmulo y por la memoria popular que insiste en el topónimo "El Castillejo" como recuerdo de las grandes piedras que allí se ubicaban. Sería igualmente lógico suponer que parte del relleno original de piedra pequeña ha desaparecido y que la altura debía ser mayor a la que hoy podemos constatar.

En la actualidad no estamos en condiciones de afirmar el modo de depósito de los enterramientos de este nivel, pues no alcanzamos las cotas inferiores en el sector Oeste del Corte 1. Esperamos cumplir este objetivo en la próxima campaña.

La fecha para nivel I de Beta, encaja con las que tenemos para el dolmen de Azután (Bueno Ramírez, 1991), sobre todo con la más antigua de ellas o con la recientemente conocida de Valdemuriel 1 (Delibes y Rojo, 1997: 400). Esta fecha ha sido realizada sobre huesos, mientras que la procedente de la cabaña es de AMS. Tenemos otra fecha de AMS de una de las estructuras de habitación que se encuentra bajo el nivel I de enterramientos: $150 \pm$ 50 BP (Beta-132916) que, simplemente debe responder a una contaminación. La desconexión entre la fecha del enterramiento y la de la cabaña de corte 2 podría explicarse si entendemos que ésta, de mayor relleno que todas las constadas en ambas campañas y en una zona de depresión del túmulo, estuvo abierta a la par que los enterramientos o parte de ellos se habían depositado y, que el fuego que observamos responde a algún tipo de actividad ritual, como proponen Delibes y Rojo (1997: 405406) para el túmulo de Rebolledo. 
Ciertamente habremos de contrastar las fechas. Más interesante nos parece la reiteración de un mismo ajuar con microlitos y láminas del que forman parte las espátulas decoradas que tenemos datadas en la Meseta Norte dentro del IV milenio a.C. (Delibeset alii, 1987). La poca cerámica documentada entronca con lo que sabemos de expresiones semejantes en el Neolítico interior (Fernández-Posse, 1980), con el interés de que poseemos algunas fechas de referencia. Así la de $3.700 \pm 80$ a.C. de la Vaquera (Zamora, 1976), ahora refrendada en parte por los últimos trabajos (Iglesiaset alii, 1996: 725).

Para el nivel II aún no disponemos de ninguna fecha, pero los materiales indican una relativa sincronía cuando menos desde el punto de vista cultural. ¿Cómo interpretar esta sincronía entre los dos grupos de enterramientos descritos con las diferencias estructurales que manifiestan? Podríamos pensar que a un enterramiento familiar originario -Nivel II- se han sumado enterramientos consecutivos de individuos ligados al mismo linaje o que pretenden asociarse a él, con lo que la diferencia entre unos y otros sería de unos cientos de años. Tendremos que sustentar esta hipótesis en datos antropológicos y de ADN, pero no deja de ser sugestiva a la luz de la utilización del espacio que hemos descrito. Otra opción es que los distintos enterramientos se hayan realizado en conjunto, constituyendo el grupo familiar de Nivel II un espacio destacado dentro del conjunto general, quizá por las razones de estirpe arriba mencionadas.

La presencia de un túmulo con enterramientos colectivos en la Meseta Sur viene a sumarse a la problemática de la variabilidad de los sistemas de enterramiento en el interior y a incidir sobre la cuestión del poco conocimiento que tenemos de los sectores menos investigados.

La asociación hábitat/enterramiento nuevamente reiterada (Delibes y Zapatero, 1996) llama la atención sobre estas situaciones de continuidad, mucho más abundantes de lo supuesto hace sólo pocos años. Nosotros mismos hemos localizado materiales en el túmulo en la última campaña deAzután que esperamos publicar en breve.

Los hábitat neolíticos del interior se están conociendo más a través de los enterramientos que de una prospección sistemática en su busca. El afán de estos grupos por argumentar su derecho a la tierra es lo que ha permitido que en los años 90 podamos acercarnos a una hipótesis de poblamiento al aire libre en el V y IV milenio a.C. en el interior de la Península que, en lo que hoy sabemos, traduce la presencia de grupos humanos en tierras de potencialidad agrícola en las que se asientan mediante cabañas perecederas, con un sistema de vuelta recurrente a los mismos lugares (Delibes y Zapatero, 1996: 342). Su interés por la demostración de la propiedad de un territorio es más visible mediante sus estructuras funerarias que mediante sus sistemas de habitación. La potencia y visibilidad del túmulo del Castillejo así lo ratifica, al igual que las construcciones dolménicas tipo Azután, que tenemos documentadas en la misma línea del Tajo.

La conexión simbólica de los túmulos sin estructura megalítica con los que sí la poseen es obvia tanto desde el punto de vista del papel de estos en el paisaje como desde el punto de vista ergológico. Los túmulos sin estructura megalítica realizados sobre zonas de habitación sugieren una conexión entre estos sistemas de enterramiento colectivo y los conocidos con unos milenios de anterioridad en los concheros de los afluentes del Tajo. Conjuntos humanos con un modo de vida más estable que el de sus predecesores, acumulan a sus muertos, normalmente en posición encogida, como los nuestros, sobre los detritus de su actividad alimenticia, es decir sobre evidencias de poblamiento del grupo y los acompañan de industria lítica: microlitos, láminas y restos de talla. A veces, incluso tienen algún fragmento de cerámica. Como recientemente manifestaba uno de nosotros (Bueno Ramírez, 1994: 91), tiene más sentido histórico proponer el origen de la ritualidad megalítica en los enterramientos colectivos del mesolítico portugués, aunque no dispongan de estructura arquitectónica, que en pequeños sepulcros de carácter individual, pues esta última propuesta es bastante contradictoria con la idea del colectivismo, de grupo, que pretende transmitir el megalitismo.

La más que posible convivencia de diversas versiones de ese modo de demostrar el asentamiento en la tierra mediante el culto a los ancestros reitera la presencia de polimorfismo arquitectónico desde los inicios del megalitismo peninsular (Bueno Ramírez, 1994: 92), con lo que ello supone de cara a la asentada idea evolucionista que ha primado para la explicación del origen del megalitismo ibérico.

Las estructuras no megalíticas al interior peninsular no son muchas, pero desde los años 80 se han dado a conocer algunas en la Meseta Norte, todas ellas de gran interés. Destacan el túmulo del Miradero (Delibes et alii, 1987), el de Rebolledo (Delibes y Rojo, 1997: 405) y los sepulcros paramegalíticos de la Velilla (Delibes y Zapatero, 1996) y

T. P., 56, n. ${ }^{\circ} 2,1999$ 
Valdemuriel. Los dos primeros son más similares al del Castillejo por su configuración no megalítica y los otros dos poseen construcciones no exactamente megalíticas y buenas fechas de referencia para interpretar nuestro yacimiento. Tanto en el Miradero como en la Velilla hay espátulas decoradas, al igual que en el Castillejo.

El túmulo del Miradero, en Villanueva de los Caballeros, Valladolid, estaba sellado por una capa de cal desigualmente compactada (Delibes et alii, 1987). Curiosamente, el medio natural del túmulo del Castillejo es la caliza que creemos ha tenido el papel de conservante de los restos óseos que han llegado hasta nosotros. Restos de madera se localizaron en las zonas marginales. Nosotros estamos analizando evidencias que nos permiten sospechar la presencia de madera.

En el Miradero, los individuos estaban en posición fetal, podían individualizarse sus ajuares y en su mayoría se encontraban a la altura de la cabeza. Lo mismo podemos decir del Castillejo. Las espátulas aparecen sólo junto a algunos personajes, lo que revierte en la poca igualdad de algunos de los enterramientos. Efectivamente, en el Castillejo las espátulas se asocian a dos enterramientos: uno de la campaña que describimos y otro, de la de este año. Estas espátulas son de uso incierto (Delibes $e t$ alii, 1987: 192), pero tanto en el Miradero como en el Castillejo poseen restos de ocre. Delibes et alii (1987: 192) proponen que pudieron haberse utilizado para espolvorear los cadáveres, función que nos parece defendible. La forma de pala curva del extremo no decorado sugiere su uso como "cucharilla" para tomar el polvo rojo y utilizarlo como corresponda.

Tenemos dos fechas para el uso del Miradero: $5.115 \pm 35$ BP y $5.155 \pm 35$ BP, 3.165 y 3.205 a.C., fechas absolutamente contemporáneas a las de sepulcros con estructuras megalíticas.

El túmulo de Rebolledo, en Sedano (Delibes y Rojo, 1997: 405-406) posee tambien varias inhumaciones que los autores interpretan como simultáneas y que fueron clausuradas mediante un fuego datado en $3.333 \pm 30$ a.C. El lecho de arcilla preparado sobre el que se asentaban los enterramientos estaba repleto de cerámica y material lítico ¿quizá evidencia de un poblamiento anterior?. Los restos se depositaron enmarcados por piedras de tamaño medio, estructura que recuerda la que hemos descrito para nuestro Nivel II. Otra fecha procedente de una hoguera lateral, que los autores interpretan como con-

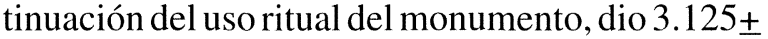

40 a. C (Delibes y Rojo, 1997: 405), lo que se aproxima bastante a la problemática de nuestras fechas.

La Velilla, en Osorno, Palencia (Delibes y Zapatero, 1996) posee una pequeña estructura central de piedras apaisadas que alberga dos depósitos funerarios: el primero de osamentas desconectadas y el segundo, de enterramientos más ordenados. Bajo el sepulcro, se localizaron cabañas sucesivas, la más antigua de las cuales se realizó en elV milenio a.C. Las más recientes, dentro del IV milenio a.C. (Delibes y Zapatero, 1996: 340) demuestran la contemporaneidad de estos hábitat al aire libre y de muchas de las construcciones dolménicas. Las diferencias de ajuar, especialmente cerámico señaladas por algunos autores (Bueno Ramírez, 1991: 112; Delibes y Zapatero, 1996: 342), han de explicarse por cuestiones de funcionalidad.

Valdemuriel, en Tubilla del Agua, posee una cámara rectangular de losas apaisadas precedida de un corredor singular. Una muestra de carbón se recogió del nivel de preparación para la construcción del sepulcro y dio 3. $720 \pm 110$. a.C (Delibes y Rojo, 1997: 400). Una fecha más antigua, 4. 615 45 a.C., se recogió a la altura de la roca madre y como los autores señalan, pese a no tener evidencias de poblamiento o actividad humana, coincide con otras del mismo tenor de la Lora burgalesa (Delibes y Rojo, 1997: 400).

Las fechas indican una clara continuidad en el poblamiento que permitiría explicar los megalitos en la dinámica de competencia por la tierra propia de las culturas productoras. Si diéramos por válida la arriba comentada (Beta 132917) de la primera mitad del IV milenio a.C. sin calibrar, conectaría con la más antigua de Azután (Bueno Ramírez, 1991), y con la de Valdemuriel (Delibes y Rojo, 1997: 400), planteando que quizá los primeros megalitos, con y sin estructura megalítica, estaban realizándose al interior de la Península en la primera mitad del IV milenio a.C., en fechas sin calibrar.

Túmulos funerarios sin estructura interior se conocen a lo largo de todo el IV milenio a.C., como venimos señalando, pero también en fechas más recientes. Este es el caso de la fosa de la Atalayuela (Andrés, 1998; Barandiarán, 1978)o de los que se están documentando en la zona centro (Blasco, 1997; Bueno Ramírez et alii, 1995; Fabián, 1995; Jiménez, 1997). De nuevo nos surge esa idea de continuidad y de polimorfismo que expresábamos arriba: hay dólmenes con ocupaciones campaniformes y hay túmulos no megalíticos con ocupaciones campaniformes. A ello hay que añadir los datos 
conocidos en las cuevas artificiales portuguesas que igualmente apuntan hacia el origen de su uso dentro del IV milenio a.C., con una ocupación muy fuerte en época campaniforme, como tenemos documentado en Huecas.

El Castillejo y su situación junto al poblado del Fontarrón nos da la oportunidad de observar la continuidad de esa secuencia Neolítico/Calcolítico pues, como dijimos arriba, el poblado posee evidencias pre y campaniformes. A ello hay que sumar la importantísima necrópolis de cuevas artificiales con campaniforme inciso y las evidencias que plantean la manufactura de cobre. Esperamos que la continuación de nuestros trabajos pueda ofrecer una perspectiva diacrónica sobre la evolución del hábitat y del mundo funerario desde el IV milenio a.C. hasta el II milenio a.C., en el valle de Huecas.

El Castillejo muestra el interés de unos pobladores neolíticos con cerámicas decoradas, por asentarse sobre una tierra poblada por sus ancestros. Su conexión con el megalitismo arquitectónico se traduce en la volumetría del túmulo y en la visualización del mismo en el entorno de un paisaje antropomorfizado. El gran hábitat del Fontarrón, anexo al hábitat antiguo posee como referencia central el túmulo del Castillejo, al igual que la necrópolis de cuevas campaniformes. Los enterramientos de los ancestros han jugado en el valle de Huecas el papel de cohesión social, de referencia ancestral, para argumentar la posesión de la tierra en un sistema de mensajes visuales que ha resultado operativo en el lugar durante más de dos milenios.

\section{AGRADECIMIENTOS}

El que estas excavaciones se hayan llevado a cabo, hemos de agradecerlo a muchas personas. En primer lugar a J.M. Rojas y R. Villa que, sabiendo de nuestro interés por estos temas en la provincia de Toledo, nos avisaron inmediatamente y pusieron a nuestra disposición los materiales documentados en su sondeo. A la Dirección de Educación y Cultura de la Junta de Castilla-La Mancha y a la Delegación de Toledo, por su rápida intervención, al Servicio de Arqueología de la Diputación de Toledo por su apoyo.Y, desde luego, a las autoridades de Huecas, que en la persona de su alcalde M.A. Lorente y de su Teniente de Alcalde, R. Félix, han constituido un apoyo en todos los sentidos para el buen desarrollo de un proyecto que esperamos poder continuar. Sin el interés expreso de la corporación en que nuestro trabajo fuera posible, hubiera sido muy difícil conseguirlo.

No podemos olvidar tampoco, la acogida que hemos tenido en la localidad, el respeto de todos los huecanos por su historia, el afán de saber y la educación que han demostrado en todo momento y que consideramos a todas luces ejemplar.

Nuestro agradecimiento a H. Rodríguez, dueño de la casa que utilizamos, al Sr. Juez de Paz que nos prestó su frigorífico, a la familia de E. Gómez de Agüero, propietarios del terreno que nos dieron todo tipo de facilidades, a la familia de M. Sánchez en cuyo negocio comimos y disfrutamos de su cordialidad y cariño. Y, sobre todo, a Rodolfo y Encarnita que estuvieron al tanto diariamente de nuestros problemas en el campo y en casa.

En los trabajos de campo participaron los miembros del Área de Prehistoria de la Universidad de Alcalá de Henares que firman este trabajo, con el apoyo diario de R. Félix, además deAmparo Aldecoa Quintana, Ana B. Casado Mateos, Víctor Martínez Palacios, Alicia Prada Gallardo, Susana Ruiz Pedraza y Natalia Suárez de la Universidad de Alcalá y Enrique Cerrillo de la Universidad de Extremadura. Los trabajos en el campo contaron con la colaboración del Ayuntamiento de la localidad en las personas de Manuel del Viso, imprescindible por su sabiduría de campo y Francisco Franco.

Al profesor Darden Hood y a todos sus colaboradores de BetaAnalytic, hemos de agradecerles el interés que han mostrado en ofrecernos toda la información posible sobre la elaboración de las muestras que han realizado.

\section{BIBLIOGRAFÍA}

Álvaro, E. (1987): "El poblamiento Calcolítico en la Meseta Sur". En El Origen de la Metalurgia en la Península Ibérica. Fundación Ortega y Gasset, II. Madrid: 16-36.

Álvaro, E.; Municio, L. y Piñón, F. (1987): "Informe sobre el yacimiento de 'Los Castillos' (Las Herencias, Toledo): un asentamiento calcolítico en la Submeseta Sur". Congreso de Historia de Castilla-la-Mancha II. Toledo, 1985: 181-197.

Álvaro, E. y Pereira, J. (1990): “El cerro del Bú (Toledo)”. Actas del Primer Congreso de Arqueología de la provincia de Toledo. Toledo: 201-213.

ANDRÉs RuPÉREZ, T. (1998): Colectivismo funerario neoeneolítico. Aproximación metodológica sobre datos de la cuenca alta y media del Ebro. Institución Fernando el Católico. Zaragoza. 
BARANDIARÁN, I. (1978): "La Atalayuela: fosa de inhumación colectiva del Eneolítico en el Ebro Medio". Príncipe de Viana, 152-153: 381-425.

Blasco Bosqued, C. (1997): "Manifestaciones funerarias de la Edad del Bronce en la Meseta". Saguntum, 30, II. Homenaje a Milagro Gil-Mascarell. Valencia: 173190.

Blasco Bosqued, C. y Rovira Llorens, S. (1993): "La metalurgia del Cobre y del Bronce en la región de Madrid". Tabona, VIII, II: 397-416.

Blasco Bosqued, C.; Sánchez Capilla, M. ål. y Calle, J. (1994): "El mundo funerario". En C. Blasco Bosqued (ed.): El horizonte Campaniforme de la región de Madrid en el centenario de Ciempozuelos. Universidad Autónoma. Madrid: 75-99.

Bueno Ramírez, P. (1990): "Megalitos en la Submeseta Sur: la provincia de Toledo". Actas del Primer Congreso de Arqueología de la Provincia de Toledo (Toledo, 1989): 127-162.

- (1991): Megalitos en la Meseta Sur: los dólmenes de Azután y La Estrella Madrid.

- (1994): "La necrópolis de Santiago de Alcántara (Cáceres). Una hipótesis de interpretación para los sepulcros de pequeño tamaño del megalitismo occidental". Boletín del Seminario de Estudios de Arte y Arqueología, LIX: 25-100.

Bueno Ramírez, P. y Balbín Behrmann, R. de. (1996): "Dólmenes en la zona Sur de la Meseta española". U. I. S. S. P. P. Series Colloquia. 9. Forli. coll. XVII. ABACO: 97-102.

Bueno Ramírez, P.; Balbín BeHrmann, R. de;Barroso BerMejo, R.;Alcolea GonZÁlez, J.J.; VillagonZÁlez, R. y Moraleda, A. (1999): El dolmen de Navalcán(Toledo). El poblamiento megalítico en el Guadyerbas. Diputación Provincial de Toledo. Servicio de Arqueología. Toledo.

Bueno Ramírez, P.; Jiménez Sanz, P. y Barroso Bermejo, R. (1995): "Prehistoria reciente en el Noreste de Guadalajara". En R. de Balbín, J. Valiente y M. Mussat (coord.): Arqueología en Guadalajara. Junta de Castilla-La Mancha. Toledo: 73-95.

Carrobles, J. (1990): "El valle bajo del río Guadarrama". En M. Fernández Miranda, J. Mangas, D. Plácido y J. Pereira: "Indigenismo y romanización en la cuenca media del Tajo. Planteamiento de un programa de trabajo y primeros resultados". Actas del Primer Congreso de Arqueología de la Provincia de Toledo(Toledo, 1989): 34-36.

Carrobles, J. y MÉndez Cabeza, A. (1991): "Introducción al estudio del Calcolítico en la Jara toledana”. Anales Toledanos, XXXVIII: 7-24.

Carrobles, J.; Muñoz, K. y Rodríguez, S. (1994): "Poblamiento durante la edad del Bronce en la Cuenca Media del Tajo". La Edad del Bronce en Castilla-la-Mancha. Diputación Provincial. Servicio de Arqueología. Toledo: 173-200.
Castañeda Clemente, N. y González Muñoz, J. (1996): "El neolítico en la Comunidad de Madrid". I Congrés de Neolitic a la Península Ibérica. Rubricatum, 1, 2: 715-719.

Criado Boado, F. y Villoch VázQuez, V. (1998): “La monumenta lización del paisaje: percepción y sentido original en el megalitismo de la Sierra de Barbanza (Galicia)". Trabajos de Prehistoria, 55(1): 63-80.

Delibes de Castro, G.; Alonso, M. y Rojo, M. (1987): "Los sepulcros colectivos del Duero medio y las Loras y su conexión con el foco dolménico riojano". El Megalitismo en la Península Ibérica. Madrid: 181-197.

Delibes de CAstro, G. y Rojo Guerra, M. (1997): “C14 y secuencia megalítica en la Lora burgalesa: acotaciones a la problemática de las dataciones absolutas referentes a yacimientos dolménicos". En A. Rodríguez Casal (ed.): O NeolíticoAtlántico e as orixes do megalitismo. Universidade de Santiago de Compostela. Santiago de Compostela: 391-414.

Delibes de Castro, G. y Zapatero Magdaleno, P. (1996): "De lugar de habitación a sepulcro monumental: una reflexión sobre la trayectoria del yacimiento neolítico de la Velilla, en Osorno (Palencia)". I Congrés de Neolitic a la Península Ibérica. Rubricatum, 1, 2: 337-348.

Esteban Caro, M.; Carrobles Santos, J. y Sánchez Ramos, J.J. (1998): Huecas. Arqueología, Historia y Arte. Diputación Provincial de Toledo. Servicio de Arqueología. Toledo.

FABIÁN GARCÍA, J.J. (1995): El aspecto funerario durante el Calcolítico y los inicios de la Edad del Bronce en la Meseta Norte. Editorial Universidad. Salamanca.

FernándeZ-Miranda, M.; Fernández-Posse, Ma ${ }^{a}$.D. y MarTín, C. (1990): "Un área doméstica de la Edad del Bronce en el poblado de"El Acequión" (Albacete)". Archivo de Prehistoria Levantina, XX: 351-362.

FERnÁNDEZ-Posse y de ARnÁIZ, M. ${ }^{2} D$. (1980): "Los materiales de la cueva delAire de Patones (Madrid)". Noticiario Arqueológico Hispánico, 10: 39-64.

Gonçalves, V. (1989): Megalitismo e metalurgia no Alto Algarve oriental. UNIARQ. Lisboa,

HARRISON, R. (1974): "Ireland and Spain in the early Bonze Age". Journal of the Royal Society of Antiquaries of Ireland, CIV: 52-73.

Harrison, R.; Quero, S.; Priego, M. ${ }^{\mathrm{a} C}$. (1975): "Beaker metallurgy in Spain"Antiquity, XLIX: 273-278.

Iglesias Martínez, J.C.; Rojo Guerra, M.A. y Álvarez PeriáÑEZ, V. (1996): "Estado de la cuestión sobre el Neolítico en la Submeseta Norte". I Congrés de Neolitic a la Péninsula Ibérica. Rubricatum. 1, 2: 721-734.

JimÉNEZ SANZ, P. (1997): “El campo tumular de La MestillaAbadón(Anguita, Guadalajara)”. En R. de Balbín Behrmann y P. Bueno Ramírez (eds.): II Congreso deArqueología Peninsular. II. Neolítico, Calcolítico y Bronce. Fundación Rei Afonso Henriques. Zamora: 333-346.

LoIson, G. (1998): "La nécropole de Pontcharaud en Basse-Auvergne”. En J. Guilaine (dir.): Sépultures d'Occi-

T. P., 56, n. ${ }^{\circ} 2,1999$ 
dent et genesés des mégalithismes. Ed. Errance. París: 189-206.

Martínez Navarrete, M. ${ }^{a} I$. (1984): "El comienzo de la metalurgia en la provincia de Madrid: la cueva y cerro de Juan Barbero (Tielmes. Madrid)". Trabajos de Prehistoria, 41: 17-91.

Montero Ruiz, I.; Rodríguez Montero, S. y Rojas RodríGuEz-Malo, J.M. (1990): Arqueometría de la provincia de Toledo: Minería y recursos minerales de Cobre. Diputación Provincial de Toledo. Servicio de Arqueología. Toledo.

Mujika, J.A. (1998): "Idolos-espátulas del País Vasco: fabricación, cronología y paralelos”. Veleia, 15: 121-144.

Muñoz LóPeZ-Astilleros, K. (1993): “El poblamiento desde el Calcolítico a la Primera Edad del Hierro en el valle medio del río Tajo". Complutum, 4: 321-336.

MuÑoz, K.; GarCíA, T. e IzQuiERDo, D. (1995): “Aportaciones al estudio de la Edad del Cobre en la Cuenca media del río Tajo". Boletín del Seminario de Arte y Arqueología, LXI: 31-50.

Pérez Arrondo, C. y López de Calle Cámara, C. (1986): Aportaciones al estudio de las culturas eneolíticas en el Valle del Ebro. II. Los orígenes de la metalurgia. Instituto de Estudios Riojanos. Logroño.

- (1986): Aportaciones al estudio de las culturas eneolíticas en el valle del Ebro I: adornos. Instituto de Estudios Riojanos. Logroño.
RoJAS RodRíGuez-MALo, J.M. (1988): "Relación hábitateconomía en el mundo campaniforme toledano". Congreso de Historia de Castilla-La Mancha, II. Talavera: 199-206.

Rojas Rodríguez-Malo, J.M. y Rodríguez Montero, S. (1990): "El Guijo: aportación al estudio del Calcolítico y la Edad del Bronce en la Cuenca Media delTajo". Actas del Primer Congreso deArqueología de la Provincia de Toledo (Toledo, 1989): 165-198. Toledo.

Rovira Llorens, S.; Montero Ruiz, I. y Consuegra RodríGUEZ, S. (1997): Las primeras etapas metalúrgicas de la Península Ibérica. I. Análisis de materiales. Instituto Ortega y Gasset. Madrid.

Rubio, I. y Blasco, C. (1988): “Análisis cerámicos de la cueva de la Vaquera (Torreiglesias, Segovia". Zephyrus, XLI-XLII: 149-160.

RuIZ FERnÁNDEZ, F. (1975): "Una necrópolis de la Edad del Bronce en Yuncos (Toledo)". Sautuola, I: 117-133.

Vegas Aramburu, J.I. (1981): "El túmulo-dolmen de Kurtzebide”. Estudios de Arqueología Alavesa, 10: 19-66

Villa González, R. y Rojas Rodríguez-Malo, J.M. (1996): “Aportación al conocimiento del Neolítico en la cuenca media del Tajo". I Congrés de Neolitic a la Península Ibérica. Rubricatum, 1, 2: 707-714.

Zamora Canellada, A. (1976): Excavaciones de la Cueva de la Vaquera. Torreiglesias. Segovia (Edad del Bronce).Excma. Diputación Provincial de Segovia. Segovia.

\section{LAS PRIMERAS ETAPAS METALURCICAS EN LA PENINSULA IBÉRICA}

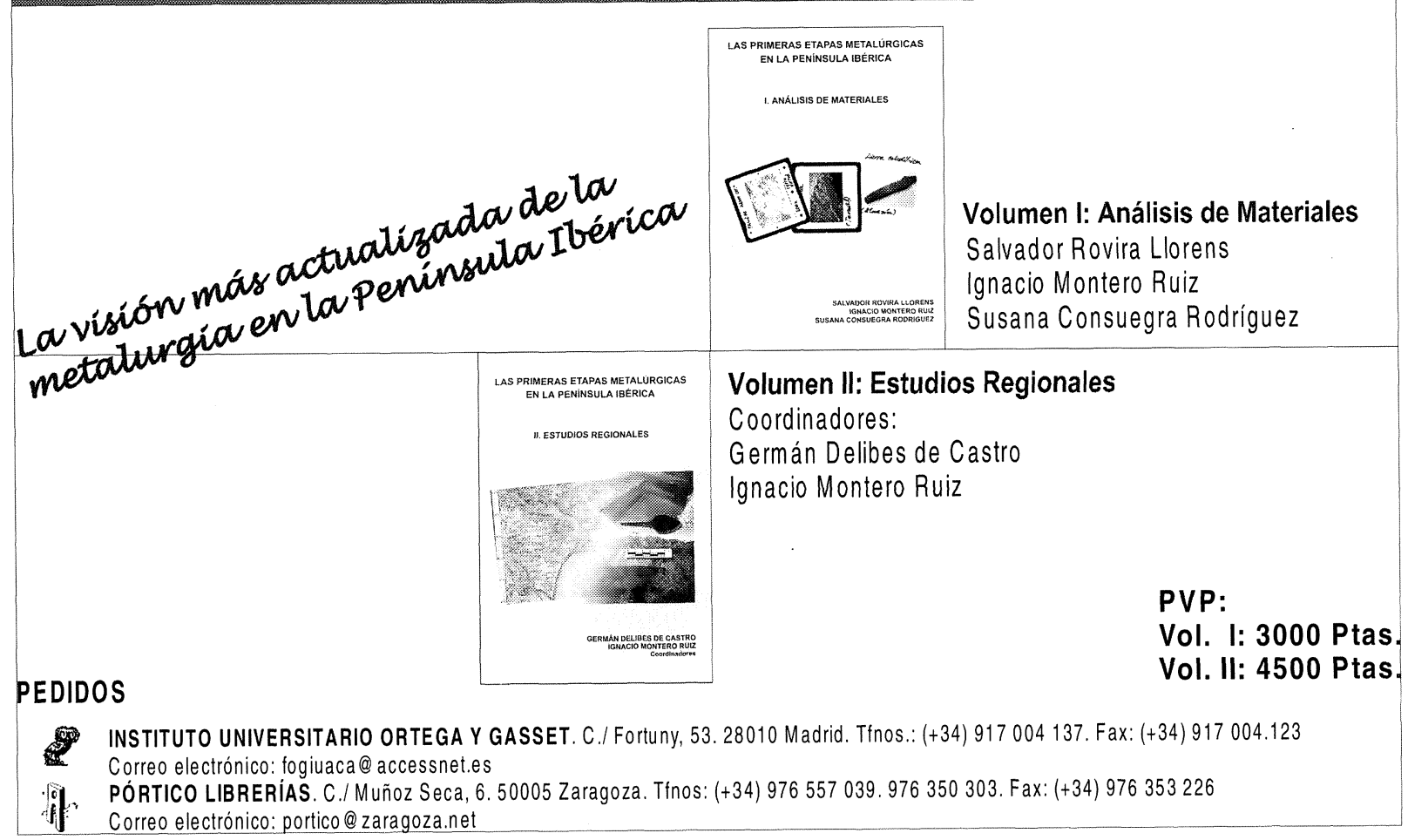

T. P., 56, n. ${ }^{\circ} 2,1999$ 